\title{
Phase Separation in Porous Media Integrated Capillary Channels
}

\section{Parabolic flight experiment results}

\author{
Kamal S. Bisht ${ }^{1}$ [D $\cdot$ Michael E. Dreyer ${ }^{1}$
}

Received: 1 June 2020 / Accepted: 30 August 2020 / Published online: 9 November 2020

(C) The Author(s) 2020

\begin{abstract}
Phase separation in space is critical for gas-free propellant supply, life support systems, refueling of spacecraft in low earth orbit (LEO), and for deep space exploration missions. In the absence of gravity, the stability of the liquid-gas interface depends on capillary forces. High liquid flow rates, sudden accelerations, and vibrational disturbances can cause the free surface of the liquid to collapse, which results in the ingestion of gas. Propellant tanks may have screen channel liquid acquisition devices (SCLADs) to position and maintain a gas-free propellant supply to the outlet. A saturated porous screen permits liquid to pass through but acts as a barrier to the gas. We investigated phase separation in porous media integrated capillary channels during parabolic flights ( $33^{\text {rd }}$ DLR parabolic flight campaign in March 2019). An open side of a rectangular channel was covered with a dutch twill weave $200 \times 1400$. The liquid was ingested into the channel from its surroundings by establishing a differential pressure across the screen section. The gas-phase was blocked during the liquid withdrawal. We could show that the gas breakthrough occurs when the pressure difference across the screen exceeds the bubble point pressure. The experimental results showed good agreement with correlations from literature.
\end{abstract}

Keywords Liquid acquisition device $\cdot$ Porous screen $\cdot$ Phase separation $\cdot$ Bubble point · Microgravity

\section{List of symbols}

Latin letters

$\triangle p_{b p} \quad$ bubble point pressure, $\mathrm{hPa}$

$\triangle p_{0} \quad$ bubble point reference pressure, $\mathrm{hPa}$

$\triangle p \quad$ differential pressure, $\mathrm{hPa}$

$\triangle p_{c t} \quad$ differential pressure in the $\mathrm{CT}, \mathrm{hPa}$

$\Delta p_{t} \quad$ differential pressure in the tube, $\mathrm{hPa}$

$b \quad$ channel width, $\mathrm{mm}$

a gap distance, $\mathrm{mm}$

$A_{0} \quad$ area of the test channel, $\mathrm{mm}^{2}$

$A_{N 1} \quad$ area of the nozzle, $\mathrm{mm}^{2}$

This article belongs to the Topical Collection: Multiphase Fluid Dynamics in Microgravity

Guest Editors: Tatyana P. Lyubimova, Jian-Fu Zhao

Kamal S. Bisht

kamal.bisht@zarm.uni-bremen.de

Michael E. Dreyer

michael.dreyer@zarm.uni-bremen.de

1 Department of Fluid Mechanics, Faculty of Production

Engineering - Mechanical Engineering and Process

Engineering, University of Bremen, ZARM,

Am Fallturm, 28359, Bremen, Germany
$A_{S_{2}} \quad$ area of the screen section $S_{2}, \mathrm{~mm}^{2}$

$B \quad$ screen thickness, $\mu \mathrm{m}$

$C_{0} \quad$ screen constant, -

$C_{1} \quad$ viscous drag coefficient, -

$C_{2} \quad$ inertial drag coefficient, -

$d_{t} \quad$ tube diameter, $\mathrm{mm}$

$D_{p} \quad$ particle retention diameter, $\mu \mathrm{m}$

$D_{b p} \quad$ bubble point diameter, $\mu \mathrm{m}$

Eu Euler number, -

$f \quad$ friction factor, -

$g_{e} \quad$ acceleration, gravity, $9.81 \mathrm{~m} \mathrm{~s}^{-2}$

$h$ measurement tube height, $\mathrm{mm}$

$h_{t} \quad$ liquid height, $\mathrm{mm}$

$l \quad$ length of the channel, $\mathrm{mm}$

$l_{1} \quad$ length of screen section $S_{1}, \mathrm{~mm}$

$l_{2} \quad$ length of screen section $S_{2}, \mathrm{~mm}$

$p_{a} \quad$ ambient pressure, bar

$p_{0} \quad$ pressure at the beginning of $S_{1}, \mathrm{hPa}$

$p_{1} \quad$ pressure at the screen section $S_{2}, \mathrm{hPa}$

$Q_{c} \quad$ flow rate in the channel, $\mathrm{mL} \mathrm{s}^{-1}$

$Q_{t} \quad$ flow rate in the tube, $\mathrm{mL} \mathrm{s}^{-1}$

$\operatorname{Re}_{p} \quad$ pore Reynolds number, -

$S \quad$ specific surface area, $\mu \mathrm{m}^{-1}$

$S_{1}, S_{2} \quad$ screen sections 


$\begin{array}{ll}t & \text { time, } \mathrm{s} \\ \Delta t & \text { time difference, } \mathrm{s} \\ T & \text { temperature, }{ }^{\circ} \mathrm{C} \\ u_{S} & \text { superficial velocity, } \mathrm{mm} \mathrm{s}^{-1} \\ X & \text { flow direction in channel, coordinate system } \\ Y & \text { coordinate system } \\ Z & \text { vertical direction, coordinate system }\end{array}$

Greek letters

$\begin{array}{ll}\mu & \text { dynamic viscosity, Pas } \\ \phi & \text { porosity, }- \\ \rho & \text { density, } \mathrm{kg} \mathrm{m}^{-3} \\ \sigma & \text { surface tension, } \mathrm{N} \mathrm{m}^{-1} \\ \tau & \text { screen tortuosity, }- \\ \theta & \text { contact angle, }{ }^{\circ}\end{array}$

\section{Subscripts}

$\begin{array}{ll}0 & \text { initial condition } \\ 1,2 & \text { first, second } \\ b p & \text { bubble point } \\ l & \text { liquid } \\ c & \text { channel } \\ t & \text { tube } \\ c t & \text { compensation tube } \\ E & \text { experiment } \\ A & \text { analytical }\end{array}$

\section{Abbreviations}

$\begin{array}{ll}\text { BP } & \text { bellow pump } \\ \text { CT } & \text { compensation tube } \\ \text { FM } & \text { flow meter } \\ \text { FP } & \text { flow pump } \\ \text { LPR } & \text { low pressure reservoir } \\ \text { LR } & \text { liquid reservoir } \\ \text { PS } & \text { phase separator } \\ \text { TV1,TV2,TV3 } & \text { throttle valves } \\ \text { V1,V2,V3,V5,V6,V7,V9 } & \text { gas valves } \\ \text { V4,V8 } & \text { liquid valves } \\ \text { VP } & \text { vacuum pump } \\ \text { CCF } & \text { capillary channel flow } \\ \text { ISS } & \text { International Space Station } \\ \text { DTW } & \text { dutch twill weave } \\ \text { SEM } & \text { Scanning Electron } \\ & \text { Microscopy } \\ \text { MSG } & \text { Microgravity Science } \\ \text { IPA } & \text { Glovebox } \\ & \text { isopropyl alcohol }\end{array}$

\section{Introduction}

In a compensated gravity environment, hydrostatic forces are diminished, and capillary forces dominate the orientation of a liquid in a spacecraft tank. Depending on the contact angle, which is usually very small for propellants, liquid adheres to the tank wall, and gas accumulates in the center. Therefore, the tank outlet is not necessarily covered with liquid all the time. The acceleration caused by the thrusters could also deposit liquid in the opposite direction. If the outlet loses the connection with liquid, the spacecraft engines can no longer be provided with propellant for its operation.

The transport of liquid to the tank outlet in a compensated gravity environment is accomplished by employing propellant management devices or PMDs. PMDs act passively and use capillary forces to operate. Based on the demand (size of the tank, propellant type), PMDs are specifically designed for each mission. PMDs can be classified into three types, as introduced by Rollins et al. (1985); a) total control, b) partial control, and c) total communication. Total control devices are non-refillable and consist of a trap that holds all of the propellants over the tank outlet. A partial control device traps a small amount of propellant over the tank outlet to restart the engine. Other devices do not constrain the remaining liquid. The acceleration exerted by the engine settles the propellant in the vicinity of the device. The walls of the partial control devices are made up of porous meshed screens, which allow the propellant to enter and refill it for further usage.

Total communication devices establish a continuous flow path between the bulk of the propellant and the tank outlet, regardless of the spin and acceleration of the spacecraft. They employ vanes, open channels, and galleries to transport and position the propellant. Vanes are thin sheets of metal positioned perpendicular or parallel to the tank wall. The liquid present in the proximity of the vanes flows through an open path to the tank outlet. Jaekle Jr. published the analysis of the design of vanes for steady and unsteady flows in 1991 (Jaekle 1991). An open capillary channel consists of closed solid walls and an open side facing the tank wall. The stability of the free surface (liquidgas interface) in the channel is determined in accordance with the Gauss-Young-Laplace equation (see Bronowicki et al. 2015). An increase in the liquid flow rate corresponds to a rise of the free surface curvature. If the flow rate exceeds a specific value, the free surface collapses, and ambient gas is ingested into the liquid. This phenomenon was studied in detail by Rosendahl et al. (2004) for a parallel plate channel aboard a sounding rocket and in the drop tower. Grah et al. (2014), Canfield et al. (2013), and Bronowicki et al. (2015) investigated capillary dominated free surface flows in different open channel geometrical shapes (parallel plate, rectangular groove, and wedge) aboard the International Space Station (ISS). The stability of the free surface may also be affected by sudden accelerations and vibrational disturbances. The presence of gas in the liquid is an unwanted feature for applications in propellant management systems. 
The limitations in the open channel design can be encountered by employing galleries, also known as screen channel liquid acquisition devices (SCLADs). In galleries, the open side of the channel is covered with a metallic porous screen. The saturated screen blocks the gas but permits the flow of the surrounding liquid into the channel. A surface tension tank may consist of several galleries positioned in the vicinity of the wall. The galleries are connected to the tank outlet and follow the wall contour to the tank top. Jaekle (1997) performed a design analysis and gave recommendations for different configurations. Hartwig and Darr (2014) showed that the SCLADs are more robust, can sustain a higher flow rate, and maintain a gas-free propellant supply against variable accelerations compared to other types of vanes.

We performed our experiment in an environment with variable accelerations to alter and partially eliminate the hydrostatic forces. This paper includes the results of a phase separation process in SCLADs. The bulk liquid from the surrounding is ingested into the channel, and a continuous gas-free propellant supply is established. The limitation of the setup was investigated during bubble point tests in micro- and hypergravity. The data can be used to improve SCLAD designs for future space missions, and to develop advanced life support and thermal systems.

\section{State of the Art}

A screen channel LAD shall always remain filled with liquid. The drained liquid from the channel to the tank outlet is replenished from the surroundings. The amount of liquid drawn into the channel through the screen depends on the pressure difference across the screen. As the liquid quantity in the tank reduces with time, the screen area in contact with the liquid also gets smaller. This leads to a higher flow rate per unit area and an increase in the pressure drop. If the differential pressure across the screen exceeds its bubble point pressure $\triangle p_{b p}$, the gas breakthrough occurs. The bubble point pressure is determined by the surface tension of the liquid, the contact angle of the liquid with the solid, and screen properties. Besides the flow-through screen pressure drop, viscous and dynamic pressure losses in the channel contribute to the differential pressure as well. The bubble point is calculated as

$\triangle p_{b p}=C_{0} \Delta p_{0}=\frac{4 \sigma \cos \theta}{D_{b p}}$

with

$\triangle p_{0}=\frac{4 \sigma \cos \theta}{D_{p}}$

$D_{b p}$ is the bubble point diameter, $D_{p}$ is the particle retention size diameter, which indicates the largest particle that can pass through the screen, $\sigma$ is the surface tension of the liquid, $\theta$ is the contact angle between the liquid and the porous material, and $C_{0}$ a constant which depends on the pore geometry and breakthrough dynamics. For cylindrical pores, $C_{0}$ is equal to 1 (Cady 1973). However, in the case of dutch twilled weaves, the pores are not cylindrical and have a complex geometry. Hartwig (2016b) showed that the pores in a dutch twilled weave are triangular in shape, using a scanning electron microscopy (SEM) image of the screen. The value for $D_{p}$, as provided by the manufacturer of the screen, is based on the largest spherical particle, which could pass the screen, and could overestimate the bubble point. If the bubble point is calculated from the value of $D_{p}$, a constant $C_{0}$ shall be added to the corresponding equation. The bubble point diameter $D_{b p}$ is calculated from the experimentally obtained bubble point pressure. It represents the true pore geometry and an effective pore diameter. The screen resistance to a gas breakthrough was investigated by Cady (1973), Hartwig et al. (2014), Hartwig and Mcquillen (2015), Hartwig (2016a), and Kudlac and Jurns (2006) for various dutch twilled weaves (DTW) using cryogenic liquids in ground-based experiments. Conrath and Dreyer (2012) measured the static and dynamic bubble point of a DTW $200 \times 1400$ screen using a silicon fluid SF0.65.

According to Armour and Cannon (1968), the flowthrough-screen pressure drop can be modeled as the sum of viscous and inertial flow pressure losses

$\Delta p=C_{1}\left(\frac{\tau B \mu S^{2}}{\phi^{2}}\right) u_{s}+C_{2}\left(\frac{\tau \rho B}{\phi^{2} D_{b p}}\right) u_{s}^{2}$

Here, $C_{1}$ and $C_{2}$ are empirical constants, which depend on the screen type; $\tau$ denotes the tortuosity of the screen, $B$ is the screen thickness, $S$ is the surface area to volume ratio of the screen, $\phi$ is the porosity, and $u_{s}$ is the superficial velocity. The superficial velocity is calculated from the flow rate approaching the screen, here $Q_{t}$, and the effective screen area, here $A_{S_{2}}$, through which the liquid can flow.

$u_{s}=\frac{Q_{t}}{A_{S_{2}}}$

Equation 3 can be transformed into a dimensionless form to compare the pressure drop of various screens by introducing a friction factor $f$ and pore Reynolds number $\operatorname{Re}_{p}$. The resulting equations read as

$f=\frac{\phi^{2} D_{b p}}{\tau B} \frac{\triangle p}{\rho u_{s}^{2}}$

$\operatorname{Re}_{p}=\frac{\rho u_{s}}{\mu S^{2} D_{b p}}$

$f=\frac{C_{1}}{\operatorname{Re}_{p}}+C_{2}$

This is the form firstly introduced by Armour and Cannon (1968). The pore Reynolds number determines whether or 
not the inertial pressure loss term (second term in Eq. 3) shall be added. It can be neglected below a Reynolds number range of $1 \leq \operatorname{Re}_{p} \leq 10$.

Conrath and Dreyer (2012) define the screen cross flow pressure drop in non-dimensional form using a Euler number $\mathrm{Eu}$, which relates $\Delta p$ to the dynamic pressure as

$\triangle p=\mathrm{Eu} \rho u_{s}^{2}$

The dynamic pressure results from the liquid density $\rho$ and the superficial velocity $u_{s}$ with which it approaches the screen. The Euler number for a woven screen is defined as

$\mathrm{Eu}=\frac{\tau B}{\phi^{2} D_{b p}}\left(\frac{C_{1}}{\operatorname{Re}_{p}}+C_{2}\right)$

The values of the empirical constants $C_{1}$ and $C_{2}$ were derived by various authors independently. Armour and Cannon (1968) studied five types of weaves in gaseous helium and nitrogen flow. They used the least square regression approach to find universal constants for all weaves. Cady (1973) performed experiments in liquid hydrogen and gaseous nitrogen in 1973. He used the same method to fit the data but obtained the coefficients for each weave type separately. Hartwig (2016b) proposed a common value for dutch twilled weaves based on his experiments with cryogenic liquids. Conrath and Dreyer (2012) found the constants for a dutch twilled weave $200 \times$ 1400 under steady flow conditions. The constants $C_{1}$ and $C_{2}$ are listed in Table 1.

Camarotti et al. (2019a) studied 14 different screen types at room temperature with storable liquids. The results show that $\triangle p_{b p}$ increases with the screen fineness and does not depend on the fluid properties. The difference between the bubble point pressure of stainless steel (304SS) DTW $200 \times$ 600 and aluminum DTW $200 \times 600$ was attributed to the manufacturing process. The model predicted friction factor $f$ and pore Reynolds number correlation $\operatorname{Re}_{p}$ showed good agreement with experimentally obtained data for all weaves except the dutch twill weave. Therefore, it was suggested to use individual empirical constants for each DTW screen instead of a universal value.

The concept of a double porous screen element for passive phase separation of liquid from gas is shown by Conrath et al. (2013) for storable liquids under terrestrial conditions, and by Pingel and Dreyer (2019) for a cryogenic liquid in microgravity.

The fluid flow inside a porous medium and the capillary driven filtration has been investigated under compensated gravity by Smirnov et al. (1999), Smirnov et al. (2003), and Dushin et al. (2018).

\section{Experimental Setup}

A test facility was developed to evaluate the phase separation and rate of liquid withdrawal into the screen channel LAD from its surroundings. The experiment design was based on the Capillary Channel Flow (CCF) experiment (Canfield et al. 2013). The CCF experiment was conducted within the Microgravity Science Glovebox (MSG) on-board the International Space Station (ISS) to study the stability of free surfaces in the open capillary channels. The experiment included two modules to investigate a wedge, a parallel plate, and a rectangular-shaped channel. The length of the open surface in the channels was varied in the range of $0.1 \mathrm{~mm} \leq l \leq 48 \mathrm{~mm}$ by employing moving sliders. In this project, we performed microgravity experiments in the drop tower of the University of Bremen and on-board the Airbus A310 aircraft during the $33^{\text {rd }}$ DLR parabolic flight campaign. The test hardware experienced $4.74 \mathrm{~s}$ of the microgravity in the drop tower and $22 \mathrm{~s}$ during the parabolic flights. This paper focuses on the results obtained during the parabolic flight experiments.

Table 1 Dutch twilled weave $200 \times 1400$ screen parameters

\begin{tabular}{llll}
\hline Property & Hartwig $(2016 \mathrm{~b})^{\mathrm{a}}$ & Cady $(1973)^{\mathrm{b}}$ & Conrath and Dreyer (2012) \\
\hline$C_{0}$ & - & 0.65 & $0.648-0.705$ \\
$C_{1}$ & 6.524 & 4.2 & 5.61 \\
$C_{2}$ & 1.0 & 0.2 & 0.33 \\
$\phi$ & 0.306 & 0.248 & 0.294 \\
$S / \mu \mathrm{m}^{-1}$ & 0.0648 & 0.065 & 0.062 \\
$B / \mu \mathrm{m}$ & 143.7 & 152.4 & 150 \\
$D_{p} / \mu \mathrm{m}$ & - & 10 & $13 \pm 1$ \\
$D_{b p} / \mu \mathrm{m}$ & 23.1 & 22.17 & 20 \\
$\tau$ & 1.3 & 1.3 & 1.28 \\
\hline
\end{tabular}

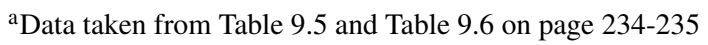

${ }^{b}$ Data taken from Table V (page 25) and Table VIII (page 40) 
The test facility includes two racks, a hydraulic rack, and an electrical rack. The hydraulic rack contains the test channel, fluid pump, flow meter, sensors, valves, and the optical system. The electrical rack consists of the process controller, the power supply distributor, and two laptop units. The electrical and hydraulic racks equipment were enclosed inside two separate aluminum containers manufactured by Zarges.

\section{Test Channel}

The geometry of the channel is shown in Fig. 1. The test channel has a rectangular shape and three closed solid walls. The open side is covered with a porous screen element at two locations. The length $l_{1}$ of the porous screen section $S_{1}$ is $48 \mathrm{~mm}$. The screen section $S_{2}$, located at $12 \mathrm{~mm}$ distance from $S_{1}$, has a circular cross-section of diameter $l_{2}=5 \mathrm{~mm}$. The width $b$ of the channel is $30 \mathrm{~mm}$, and the gap distance $a$ is $5 \mathrm{~mm}$.

A measurement tube of diameter $d_{t}=5 \mathrm{~mm}$ and length $h=100 \mathrm{~mm}$ is positioned over the screen section $S_{2}$. The tube was filled with liquid before each test to observe the rate of liquid withdrawal into the channel. The saturated screen section $S_{1}$ is exposed to ambient pressure $p_{a}$. The total length $l$ of the channel is $65 \mathrm{~mm}$, measured from the beginning of $S_{1}$ to the end of $S_{2}$. The direction of the liquid flow in the channel is shown with an arrow in Fig. 1. The channel and the measurement tube were made up of acrylic to see the liquid meniscus.

\section{Screen}

The performance of the LAD to deliver a gas-free propellant supply depends on the screen characteristics. An ideal screen should be light in weight, have a high bubble point pressure, and a fast wicking rate. Camarotti et al.
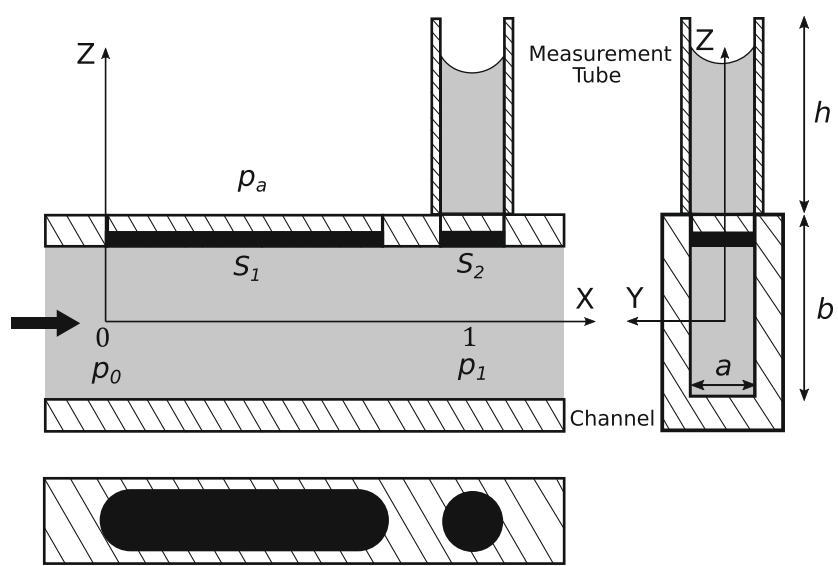

Fig. 1 Illustration of the channel geometry. The gray color represents the liquid in the test channel and the measurement tube. The black color depicts the porous screen element. The thicker black arrow illustrates the direction of the liquid flow (2019b) investigated the screen compliance as a function of mesh fineness, metal type, and open area in a transient flow regime. They concluded that in applications, where SCLADs are exposed to frequent engine restarts or sudden pressure change, meshes with smaller pore diameter and higher ability to bend exhibit better performance compared to other screen types. Darr and Hartwig (2014) list the influencing factors to select an optimal screen. They conclude that a dutch twill weave is best suited for screen channel LAD. Warp and weft wires are woven perpendicular to each other in a dutch twilled weave, which creates a small pore diameter and tortuous path for the gas flow. Hence, the bubble point threshold of the DTW screen is higher compared to other weaves. We have chosen the DTW $200 \times 1400$ screen as the porous medium for $S_{1}$ and $S_{2}$ in our experiments. A CAD model of the screen is depicted in Fig. 2.

The stainless steel screen has 200 warp wires (light gray color) and 1400 weft wires (dark gray color) per square inch. The warp wires have a diameter of $70 \mu \mathrm{m}$, while the weft wires have a diameter of $40 \mu \mathrm{m}$ (Fries et al. 2008). The characteristic properties of the screen are listed in the Table 1. Conrath and Dreyer (2012) calculated the properties from reference equations of Armour and Cannon (1968). The value for $D_{p}$ was taken from the manufacturer Spoerl, Germany (Spoerl 2019). The data from Cady (1973) is based on the same set of equations. Hartwig calculated the screen properties from newly derived equations in 2016 Hartwig (2016b). The pore diameter was obtained from a fit to bubble point experiment data.
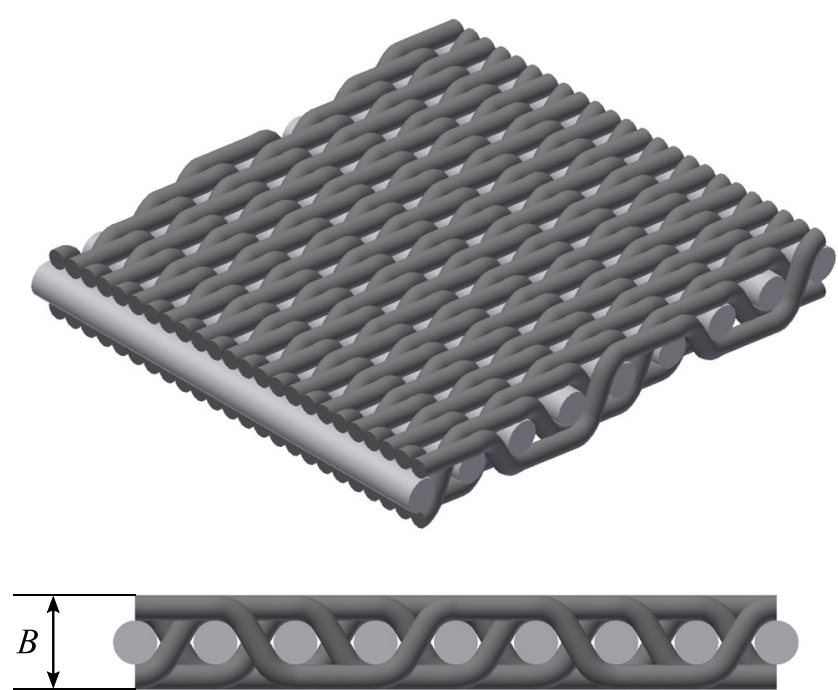

Fig. 2 3D CAD model of a dutch twilled weaves (DTW) $200 \times 1400$ screen. The warp wires are shown in light gray color, the weft wires in dark gray color 


\section{Effective Area of the Screen Section $S_{2}$}

The porous screen was fixed to the test channel with JFM 1675 Class B fuel tank sealant, supplied by PPG Aerospace. A part of the screen section $S_{2}$ was blocked with sealant (black color), as shown in Fig. 3. The open area $A_{S_{2}}$ of the screen section $S_{2}$, through which liquid flows from the measurement tube into the test channel, was calculated to $17.8 \mathrm{~mm}^{2}$. The effective $A_{S_{2}}$ was approximately $9.3 \%$ smaller than the original area for $d_{t}=5 \mathrm{~mm}$.

\section{Test Liquid}

$3 \mathrm{M}^{\mathrm{TM}}$ Novec $^{\mathrm{TM}}$ Engineering Fluid HFE-7500 was selected as test liquid for the experiment. It is non-flammable and primarily used for heat transfer applications in electrical equipment. The contact angle $\theta$ of HFE-7500 with the acrylic channel and stainless steel porous screen is $0^{\circ}$. The properties of the HFE-7500 at various temperature regimes are listed in Table 2. The surface tension of the liquid can be calculated as $\sigma=\left(19.12-0.098 \mathrm{~T} /{ }^{\circ} \mathrm{C}\right) 10^{-3} \mathrm{~N} \mathrm{~m}^{-1}$ as a function of temperature.

\section{Fluid Loop}

The fluid loop with hydraulic components, valves, temperature, and pressure sensors is shown in Fig. 4. The black color represents the liquid lines and the gray color the gas lines. The liquid from the test channel flows through the pump (FP), the flow meter (FM), the phase separator (PS), and then re-enters the test channel. The direction of the liquid flow is depicted with arrows. A Micropump GA-T23 gear pump head drives the liquid flow. The flow rate is measured with a SIKA VG 0,02 VA volume flow rate sensor.

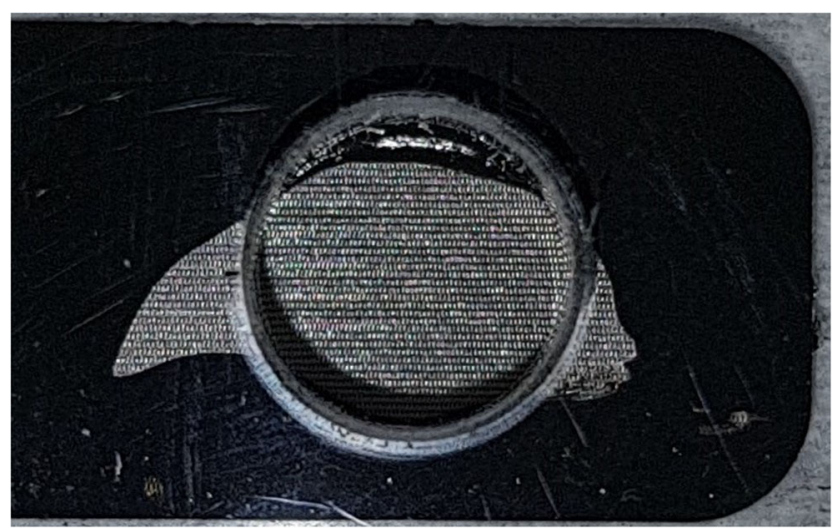

Fig. 3 Screen section $S_{2}$ after the application of sealant (black color). The sealant covers a part of the screen in the open cross section of the measurement tube. Other parts below the top plate are not glued, and may create an alternative path for the liquid flow, as we will discuss at the end of this study
The accuracy of the sensor is $\pm 3 \%$ of the measured value, as given by the manufacturer.

The test section upstream of the channel consists of the entrance nozzle and the entrance duct. The entrance nozzle is $30 \mathrm{~mm}$ long and has an elliptical profile in the $X Y$-plane. The area of the nozzle at the inlet section is $A_{N 1}=900 \mathrm{~mm}^{2}$ and converges towards the entrance duct. A partially developed flow exits the nozzle and then develops further in the entrance duct before entering the test channel. The entrance duct is $32 \mathrm{~mm}$ long, and has a cross-sectional area identical to the area of the test channel $A_{0}=150 \mathrm{~mm}^{2}$. The $58 \mathrm{~mm}$ long exit duct at the end of the test channel converges to an area of $19.63 \mathrm{~mm}^{2}$.

The phase separator PS is made of acrylic and designed to ensure gas-free liquid in the test channel. The PS consists of a DTW $200 \times 1400$ porous screen element of $90 \mathrm{~mm}$ diameter, which acts as a barrier to the gas phase and prevents it from entering into the test channel. The PS has a working volume of $267 \mathrm{~mL}$ upstream and $178 \mathrm{~mL}$ downstream of the screen element. The ingested gas bubbles through $S_{1}$ are collected and separated from the liquid in the phase separator. The accumulated gas can be removed via the gas line located at the top section of the PS.

The liquid reservoir (LR) is filled before the experiment and used to remove the trapped gas volume between the entrance nozzle and PS. The LR has a total working volume of $62.83 \mathrm{~mL}$.

The ambient and liquid temperatures are measured using PCA type PT100 sensors from JUMO. The sensors have an accuracy of $\pm 0.05{ }^{\circ} \mathrm{C}$. The inlet liquid temperature is monitored in the line entering the PS (T1) and at the outlet of the test channel (T2). The ambient temperature is measured in the gaseous environment near the compensation tube CT. The CT is made up of acrylic and has a diameter of $60 \mathrm{~mm}$, a height $70 \mathrm{~mm}$, and a total working volume of $142 \mathrm{~mL}$. The CT is partially filled with liquid and connected to the downstream side of the PS by a $180 \mathrm{~mm}$ long tube with an inner diameter of $7.75 \mathrm{~mm}$. The gaseous phase section of the CT connects to the low-pressure reservoir (LPR) by a $1280 \mathrm{~mm}$ long tube of $4 \mathrm{~mm}$ diameter. The LPR is a CRVZS- 0.75 air reservoir manufactured by Festo. The operating range of the reservoir is 0.05 bar to 16 bar as given by the supplier. The CT with the LPR is used to set the inlet boundary condition in the test channel. The CT also acts as a reservoir for the displaced liquid, when gas is ingested into the liquid line. The differential pressure in the gaseous region of the $\mathrm{CT}$ and at the top section of the measurement tube is monitored with a HCXM050D6V series differential pressure sensor, manufactured by First Sensor. The sensors have a measurement range of 0 mbar to $50 \mathrm{mbar}$ and accuracy of $\pm 25 \mathrm{~Pa}$, as given by the manufacturer. The ambient pressure was measured with an Analogue Pressure Transmitter (ATM) absolute pressure 
Table 2 Density $\rho$, dynamic viscosity $\mu$, and surface tension $\sigma$ of HFE-7500 at different temperatures $T$

\begin{tabular}{|c|c|c|c|c|}
\hline$T /{ }^{\circ} \mathrm{C}$ & $\rho / \mathrm{kg} \mathrm{m}^{-3}$ & $\mu / 10^{-3}$ Pas & $\sigma / \mathrm{N} \mathrm{m}^{-1}$ & Source \\
\hline 15.0 & 1641 & 1.49 & 0.0176 & Rosendahl and Dreyer (2007) \\
\hline 20.0 & 1631 & 1.37 & 0.0172 & Rosendahl and Dreyer (2007) \\
\hline 25.0 & 1620 & 1.25 & 0.0167 & Canfield et al. (2013) \\
\hline 30.0 & 1610 & 1.15 & 0.0162 & Canfield et al. (2013) \\
\hline
\end{tabular}

The contact angle $\theta$ of HFE-7500 with the acrylic channel and the porous screen is $0^{\circ}$

sensor, manufactured by Tetratec. The range of the sensor is 0 bar to 1.6 bar with an accuracy of \pm 2.1 mbar.

A plunger-type bellow pump (BP) acts as a liquid reservoir to maintain the correct liquid level in the test channel and the CT. The BP is filled with liquid and connected to the PS by a $560 \mathrm{~mm}$ long tube of $4 \mathrm{~mm}$ diameter. The bellow pump is a custom-made piece of hardware.

\section{Electrical Subsystem}

The electrical subsystem contains the process controller and the power supply distributor. The experiment computer is a cRIO-9047 controller from National Instruments equipped with 4 GB RAM and a $1.6 \mathrm{GHz}$ Intel Atom E3940 QuadCore processor. The power supply distributor coverts the $230 \mathrm{~V}$ AC input voltage to the $24 \mathrm{~V}$ DC output voltage and distributes it to the process controller and the experiment equipment. The total power consumption to run the experiment was measured as $270 \mathrm{~W}$.

\section{Optics}

The optical system consists of three CMOS cameras (CAM1, CAM2, CAM3) from Imagingsource and two Stemmer Imaging LED light panels. CAM1 focuses on the lower section of the measurement tube and the

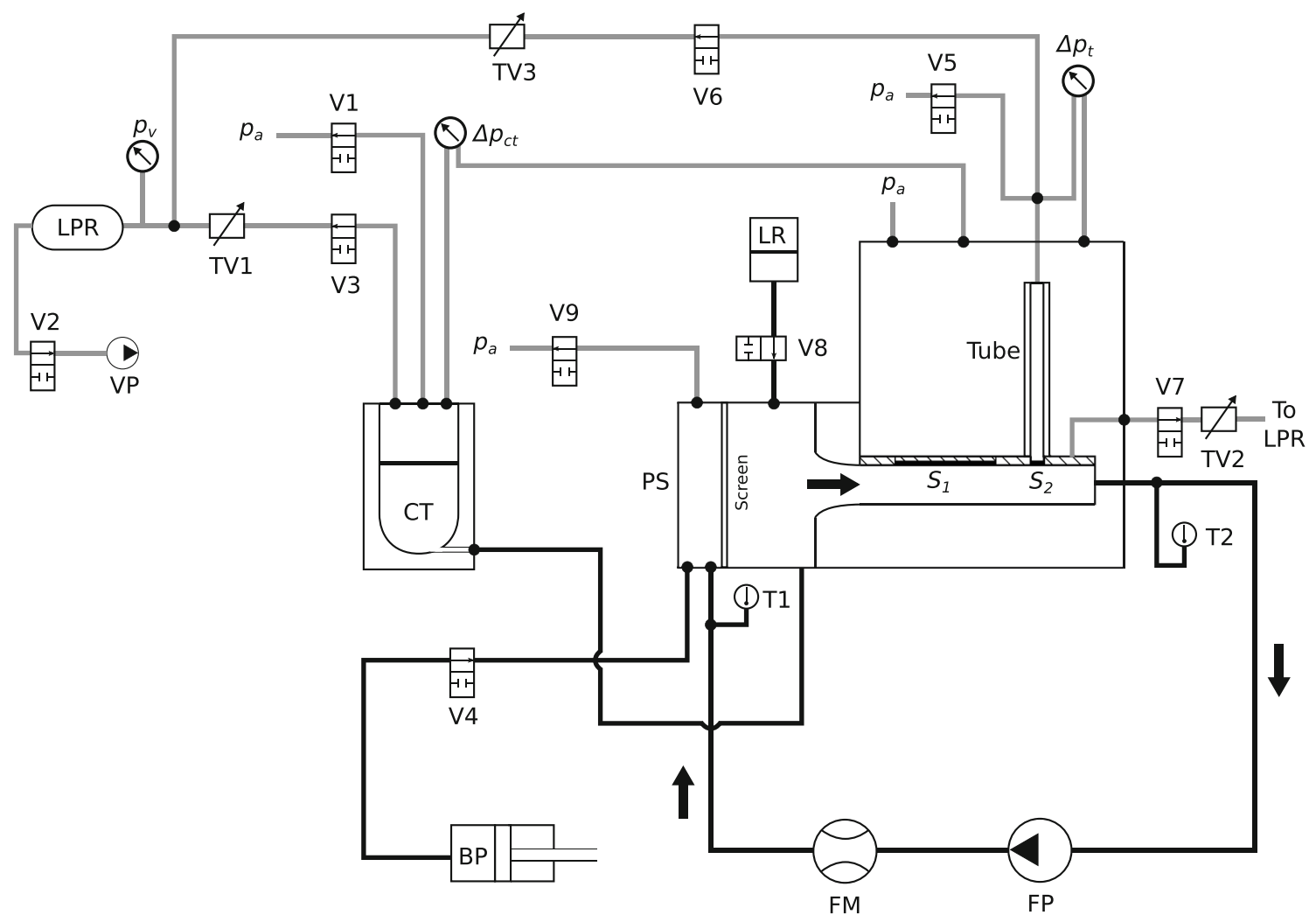

Fig. 4 Illustration of the fluid loop. The liquid lines (black in color), gas line (gray in color) and main components in the experiments are shown. The components are compensation tube (CT), phase separator (PS), fluid pump (FP), flow meter (FM), bellow pump (BP), vacuum pump (VP), liquid reservoir (LR), low pressure reservoir (LPR), throttle valves (TV1, TV2, TV3), liquid valves (V4, V8), gas valves (V1, V2, V3, V5, V6, V7, V9) 
rectangular channel to observe the occurrence of the bubble breakthrough under the screen section $S_{1}$. The field of view of CAM1 was $96 \mathrm{~mm}$ by $54 \mathrm{~mm}$. CAM 2 monitors the liquid level in the measurement tube and the screen section $S_{2}$. It covers an area of $131.5 \mathrm{~mm}$ by $74 \mathrm{~mm}$. CAM3 focuses on the compensation tube to assist in maintaining the correct liquid level. The test section is illuminated with LED panels positioned parallel to the test channel and the compensation tube to produce sharp images of the liquid meniscus. The LEDs have a wavelength of $635 \mathrm{~nm}$, which matches the spectral sensitivity of the cameras. During the entire parabolic flight, the cameras provided live video feedback of the test channel and the CT to Laptop 2. When triggered, the cameras record gray-scale images at 41 frames per second in a synchronized manner for $29 \mathrm{~s}$. The resolution of each camera unit was set to $1920 \times 1080$ pixels per image. The measurement tube is marked with a black and white scale to determine the liquid height. Each marking on the tube represented a length of $5 \mathrm{~mm}$.

\section{Experiment Preparation}

\section{Liquid Filling}

The experiment cell was filled with liquid before transportation and installation of the hardware in aircraft. After the installation, additional liquid was added through the compensation tube, entered into the phase separator, the test channel, and the lines shown in black color in Fig. 4. The displaced gas could escape from the screen sections $S_{1}$ and $S_{2}$. After the test section was filled, a steady liquid-gas interface was established in the compensation tube. Due to the hydrostatic head, the height of the liquid meniscus in the compensation tube corresponds to the liquid level in the test channel. When the experiment cell is filled completely, the screen sections $S_{1}$ and $S_{2}$ are saturated and become impermeable to the gas phase. The trapped gas in the vicinity of the screen sections $S_{1}$ and $S_{2}$ was removed by running the fluid pump and establishing a liquid flow in the channel. The gas bubbles were carried away with the liquid and accumulated at the exit duct. The exit duct has a bore of $4.134 \mathrm{~mm}$ diameter, located at $14.93 \mathrm{~mm}$ distance from the screen section $S_{2}$, on its top surface. This bore is connected to the LPR through valve V7. The removal of the gaseous phase was performed by opening the valve V7, which applies the LPR suction pressure on the collected gas volume. A throttle valve TV2, positioned between the LPR and valve V7, controls the magnitude of the suction pressure to prevent liquid ingestion with the gas. On the upstream side of the channel, the collected gas volume between the PS and entrance nozzle is exchanged with the LR liquid by operating valve $\mathrm{V} 8$.

\section{Hardware Installation}

After filling the experiment cell with the test liquid, the hardware was installed in the aircraft. The aircraft coordinate axis system is described as follows: $x$ direction from tail to front, $y$ direction from left to right, $z$ direction from floor to ceiling. Information of previous experiments and the parabolic flight manual suggest, that the $y$-axis of the plane is subjected to the smallest residual acceleration. Therefore, we aligned the flow direction or $x$-axis of our test channel with the $y$-axis of the aircraft coordinate system. The experiment coordinate system is aligned as follows: $x$ direction from left to right-wing, $y$ direction from tail to front, and $z$ direction from floor to ceiling.

\section{Experiment Procedure}

The differential pressure between the ambient and the LPR is always maintained in the range of 0.2 bar to 0.25 bar to control the suction pressure magnitude. During the experiments, the cabin pressure in the aircraft dropped to approximately 0.85 bar. Therefore, the absolute pressure of the LPR was regulated to 0.6 bar by operating a swing piston vacuum pump NPK 09 DC, supplied from KNF with valve V2. For each parabola flight profile, the test facility is exposed to both microgravity and hypergravity environments. The $22 \mathrm{~s}$ of the microgravity phase is preceded and followed by a $1.8 g_{e}$ hypergravity phase for approximately $24 \mathrm{~s}$. The transition time between the hypergravity and microgravity phase was approximately $4 \mathrm{~s}$.

\section{Before Each Parabola}

Initially, valves V1 and V5 are opened to set the test channel pressure to equilibrium with the ambient pressure and then closed. Afterward, valve V3 was opened, which depressurizes the CT by exposing it to the low pressure of the LPR. The CT is connected to the PS via a liquid line, thus, the pressure in the channel also reduces. The rate of depressurization is controlled by a throttle valve TV1. If the liquid is at rest, the pressure in the entire channel and CT remains the same. A differential pressure sensor connected to the gaseous area of the $\mathrm{CT}$ and the housing of the test channel measures the pressure $\Delta p_{c t}$, as shown in Fig. 4. The applied differential pressure was selected to be less than the bubble point pressure of the screen element to avoid gas breakthrough into the channel through the screen sections $S_{1}$ and $S_{2}$. The fluid pump FP located downstream of the channel provides the liquid flow. The flow rate is set to a predefined value for each parabola and monitored with the flow meter FM. To raise the liquid level in the measurement tube, valve V6, connecting the top section of the measurement tube to the LPR, was opened. 
Table 3 Experiment parameters at the opening time of valve V5 for flight day 1 (except for the first eleven experiments)

\begin{tabular}{lllll}
\hline Exp. ID & $\Delta p_{c t} / \mathrm{hPa}$ & $Q_{c} / \mathrm{mL} \mathrm{s}^{-1}$ & $h_{t} / \mathrm{mm}$ & $T /{ }^{\circ} \mathrm{C}$ \\
\hline F1P1 & 0.0 & 0.0 & 0.0 & 14.5 \\
F1P2 & 0.0 & 0.0 & 0.0 & 14.9 \\
F1P3 & 0.0 & 0.0 & 0.0 & 15.3 \\
F1P4 & 4.0 & 0.0 & 3.7 & 15.6 \\
F1P5 & 6.2 & 0.0 & 38.8 & 15.9 \\
F1P6 & 0.0 & 10.1 & 0.0 & 15.4 \\
F1P7 & 0.0 & 14.8 & 0.0 & 15.8 \\
F1P8 & 9.7 & 0.0 & 0.0 & 16.2 \\
F1P9 & 20.9 & 0.0 & 0.0 & 16.6 \\
F1P10 & 29.7 & 0.0 & 0.0 & 17.0 \\
F1P11 & 9.4 & 10.1 & 0.0 & 16.9 \\
F1P12 & 13.8 & 0.0 & 30.6 & 17.3 \\
F1P13 & 15.7 & 0.0 & 61.5 & 17.7 \\
F1P14 & 9.4 & 5.7 & 65.5 & 17.5 \\
F1P15 & 13.0 & 4.6 & 95.0 & 17.6 \\
F1P16 & 8.4 & 5.2 & 32.7 & 18.4 \\
F1P17 & 7.2 & 10.1 & 37.9 & 18.6 \\
F1P18 & 10.7 & 10.1 & 65.2 & 18.9 \\
F1P19 & 12.7 & 10.1 & 31.2 & 19.2 \\
F1P20 & 13.0 & 15.1 & 65.5 & 19.5 \\
F1P21 & 17.3 & 5.0 & 32.3 & 20.0 \\
F1P22 & 11.7 & 15.3 & 37.0 & 20.3 \\
F1P23 & 9.4 & 15.3 & 61.0 & 20.7 \\
F1P24 & 9.0 & 15.4 & 42.2 & 21.0 \\
F1P25 & 15.0 & 10.2 & 66.5 & 21.3 \\
F1P26 & 17.5 & 15.2 & 28.4 & 22.0 \\
F1P27 & 18.9 & 9.8 & 35.7 & 22.2 \\
F1P28 & 26.0 & 10.2 & 0.0 & 22.4 \\
F1P29 & 26.3 & 15.4 & 15.4 & 22.6 \\
F1P30 & 26.6 & & & \\
\hline & & & & \\
\hline
\end{tabular}

$\triangle p_{c t}$ is the differential pressure in CT, $Q_{c}$ is the flow rate in the channel, $h_{t}$ is the liquid height in the measurement tube, and $T$ is the liquid temperature. Experiment IDs in bold letters indicate hypergravity experiments

The LPR applies a suction pressure on the top end of the measurement tube, and liquid from the channel moves out into the tube. The pressure $\Delta p_{c t}$ reduces further due to the suction pressure of the LPR. The liquid level in the tube was monitored via live video feedback of CAM2. The valve V6 was closed when the liquid level in the tube reached the desired height. A differential pressure sensor located at the top section of the measurement tube measures the pressure $\Delta p_{t}$. The measured value of $\Delta p_{t}$ was always higher than $\Delta p_{c t}$. The difference is due to the hydrostatic head of the liquid column in the tube. At $t=-10 \mathrm{~s}$ before the start of the parabola, the sensor
Table 4 Experiment parameters at the opening time of valve V5 for flight day 2

\begin{tabular}{lllll}
\hline Exp. ID & $\Delta p_{c t} / \mathrm{hPa}$ & $Q_{c} / \mathrm{mL} \mathrm{s}^{-1}$ & $h_{t} / \mathrm{mm}$ & $T /{ }^{\circ} \mathrm{C}$ \\
\hline F2P1 & 12.7 & 10.0 & 0.0 & 15.0 \\
F2P2 & 15.1 & 0.0 & 55.7 & 15.4 \\
F2P3 & 16.9 & 0.0 & 66.2 & 15.7 \\
F2P4 & 11.7 & 5.3 & 66.8 & 15.5 \\
F2P5 & 27.4 & 10.9 & 41.0 & 15.7 \\
F2P6 & 30.9 & 10.9 & 35.5 & 16.0 \\
F2P7 & 16.9 & 5.0 & 92.0 & 16.5 \\
F2P8 & 10.1 & 5.0 & 48.8 & 16.6 \\
F2P9 & 10.4 & 12.0 & 41.8 & 16.9 \\
F2P10 & 13.9 & 10.5 & 72.0 & 17.2 \\
F2P11 & 25.4 & 15.7 & 71.8 & 17.6 \\
F2P12 & 14.9 & 10.2 & 46.0 & 18.2 \\
F2P13 & 17.0 & 15.9 & 72.1 & 18.6 \\
F2P14 & 19.2 & 5.2 & 38.3 & 18.8 \\
F2P15 & 13.3 & 14.8 & 38.4 & 19.1 \\
F2P16 & 27.7 & 10.2 & 91.6 & 19.4 \\
F2P17 & 13.5 & 5.0 & 72.1 & 20.1 \\
F2P18 & 11.6 & 15.0 & 56.6 & 20.4 \\
F2P19 & 16.5 & 10.2 & 64.5 & 20.6 \\
F2P20 & 20.7 & 15.4 & 48.1 & 20.9 \\
F2P21 & 28.1 & 15.3 & 34.1 & 21.3 \\
F2P22 & 18.7 & 15.4 & 40.2 & 22.0 \\
F2P23 & 22.1 & 15.4 & 72.2 & 22.3 \\
F2P24 & 26.9 & 10.2 & 64.0 & 22.5 \\
F2P25 & 32.0 & 10.2 & 71.4 & 22.7 \\
F2P26 & 24.4 & 10.2 & 95.8 & 22.9 \\
F2P27 & 25.0 & 10.0 & 0.0 & 23.2 \\
F2P28 & 24.6 & 15.2 & 0.0 & 23.5 \\
F2P29 & 28.0 & 15.2 & 15.2 & 24.0 \\
F2P30 & 32.0 & 15.0 & 24.4 \\
F2P31 & 25.0 & & & \\
\hline & & & & \\
\hline
\end{tabular}

output data was triggered to be recorded with $100 \mathrm{~Hz}$. During the microgravity phase, the hydrostatic head of the liquid column in the measurement tube becomes negligible; thus, $\Delta p_{t}$ reduces and establishes an equilibrium with $\triangle p_{c t}$.

\section{During Each Parabola}

CAM1, CAM2, and CAM3 are triggered to record images. If valve V5 opens, it exposes the liquid in the measurement tube to the ambient pressure. The withdrawal of liquid starts. If the liquid level in the tube reaches the screen section $S_{2}$, valve V5 was closed. For bubble point experiments, only valve V6 was operated during parabola, and all other valves remain closed. 


\section{Results}

We performed 91 experiments during the $33^{\text {rd }}$ parabolic flight campaign of DLR (March 2019). We gathered quantitative data on the phase separation capability of the screen channel liquid acquisition device. The experiment was operated on-board by a team of two persons. The temperature, absolute and differential pressure sensor data were recorded continuously for the complete flight on each day at 10 $\mathrm{Hz}$ rate, and at $100 \mathrm{~Hz}$ during the parabola. The maximum flow rate in the channel was limited to $15.7 \mathrm{~mL} \mathrm{~s}^{-1}$. The phase separator operated successfully. We removed the ingested gas after the aircraft had landed.

The differential pressure in the CT $\triangle p_{c t}$, the liquid flow rate in the channel $Q_{c}$, and the liquid column height $h_{t}$ in the measurement tube were used for the parametric study. We

Table 5 Experiment parameters at the opening time of valve V5 for flight day 3

\begin{tabular}{lllll}
\hline Exp. ID & $\Delta p_{c t} / \mathrm{hPa}$ & $Q_{c} / \mathrm{mL} \mathrm{s}^{-1}$ & $h_{t} / \mathrm{mm}$ & $T /{ }^{\circ} \mathrm{C}$ \\
\hline F3P1 & 7.7 & 10.1 & 0.0 & 15.0 \\
F3P2 & 12.6 & 0.0 & 31.2 & 15.5 \\
F3P3 & 17.1 & 0.0 & 64.5 & 15.8 \\
F3P4 & 7.6 & 5.0 & 65.0 & 15.7 \\
F3P5 & 21.5 & 10.0 & 91.0 & 15.8 \\
F3P6 & 13.8 & 5.0 & 91.2 & 16.2 \\
F3P7 & 8.0 & 5.0 & 36.7 & 16.4 \\
F3P8 & 7.6 & 10.1 & 33.0 & 16.8 \\
F3P9 & 10.3 & 10.1 & 62.3 & 16.9 \\
F3P10 & 23.7 & 15.0 & 63.3 & 17.2 \\
F3P11 & 15.0 & 10.0 & 40.4 & 18.0 \\
F3P12 & 16.2 & 15.2 & 66.2 & 18.4 \\
F3P13 & 19.8 & 5.0 & 36.3 & 18.6 \\
F3P14 & 12.6 & 15.0 & 36.6 & 18.9 \\
F3P15 & 26.4 & 5.0 & 0.0 & 19.2 \\
F3P16 & 8.8 & 15.0 & 58.5 & 20.1 \\
F3P17 & 9.8 & 15.0 & 44.5 & 20.4 \\
F3P18 & 15.2 & 9.8 & 57.2 & 20.7 \\
F3P19 & 16.0 & 15.2 & 41.7 & 21.0 \\
F3P20 & 25.5 & 10.0 & 0.0 & 21.4 \\
F3P21 & 17.2 & 15.2 & 34.5 & 22.1 \\
F3P22 & 19.8 & 15.2 & 67.8 & 22.5 \\
F3P23 & 24.4 & 10.0 & 62.5 & 22.7 \\
F3P24 & 29.2 & 10.0 & 59.0 & 22.9 \\
F3P25 & 25.5 & 15.2 & 0.0 & 23.2 \\
F3P26 & 23.2 & 10.0 & 0.0 & 23.7 \\
F3P27 & 23.0 & 15.2 & 0.0 & 24.0 \\
F3P28 & 25.0 & 15.2 & 10.0 & 23.3 \\
F3P29 & 24.8 & 10.0 & 24.5 \\
F3P30 & 31.0 & & & \\
\hline & & & & \\
\hline
\end{tabular}

Experiment IDs in bold letters indicate hypergravity experiments state all test parameters in Tables 3, 4 and 5. Experiments with IDs F1P1, F1P3, F1P4, F3P29, and F3P30 were performed in the hypergravity phase (indicated with bold letters in Tables 3 and 5) to investigate the sustainability of the device in cases of sudden acceleration and vibrational disturbances. All other experiments were conducted in the partly compensated phase of the flight. The first eleven experiments in Table 3 focused on the observation of the behavior of the system in a variable gravity environment. For those experiments, valve V5 remained closed, and the sensors and cameras were triggered to record the images and data. The liquid temperature is monitored by temperature sensors $\mathrm{T} 1$ and $\mathrm{T} 2$ at the inlet and outlet lines during the experiment (See Fig. 4). As seen in Tables 3, 4 and 5, the liquid temperature increased over time due to heat generated by the fluid pump FP.

\section{Differential Pressure and Gravity Variation}

The differential pressures $\Delta p_{c t}$ and $\Delta p_{t}$, as well as the acceleration in $z$-direction are shown in Fig. 5 for ID F3P18. At $t=-40 \mathrm{~s}$, the temperature, pressure and flow rate sensors recording was switched to $100 \mathrm{~Hz}$. The first hypergravity phase was initiated at approximately $t=-30 \mathrm{~s}$. The acceleration in $z$-direction increased to 1.8 times the gravitational acceleration on Earth. This caused an increase of the hydrostatic head in the measurement tube. The differential pressure $\Delta p_{t}$ increased from $23 \mathrm{hPa}$ to $26 \mathrm{hPa}$, and then reduced during the transition phase.

The compensated gravity phase began at $t=-2 \mathrm{~s}$, and ended at $t=19 \mathrm{~s}$. In that phase, the hydrostatic

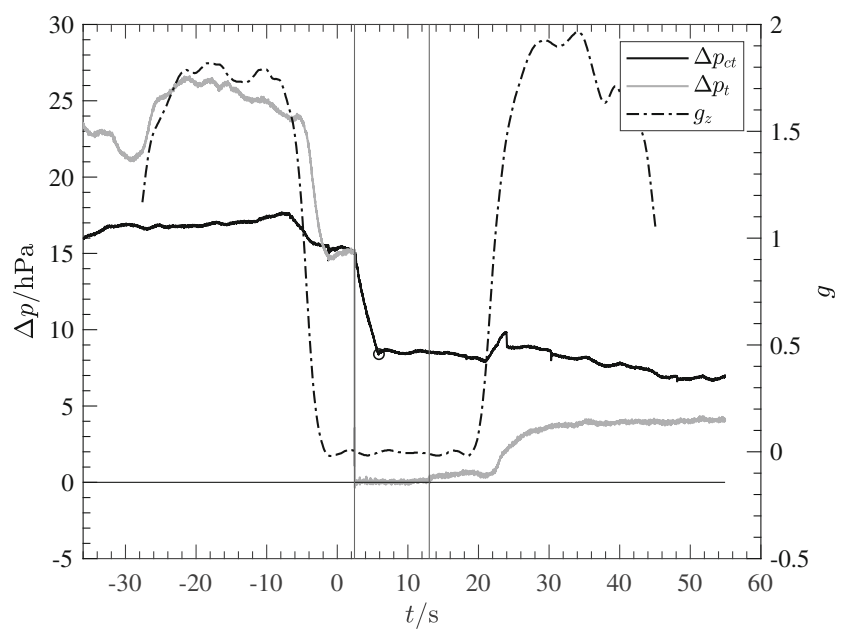

Fig. 5 Differential pressures $\Delta p_{c t}$ and $\Delta p_{t}$, and acceleration in $z$ direction during the parabola with ID F3P18. The vertical axis $z$ in our experimental setup is identical to the vertical axis of the aircraft. The reference value is the gravitational acceleration on Earth with the value $9.81 \mathrm{~m} \mathrm{~s}^{-2}$. The first vertical line from the left represents the opening time of valve V5, the second line its closure. The circular mark depicts the time when the liquid meniscus in the measurement tube reaches the screen 
head of the liquid column in the measurement tube became negligible, and an equilibrium state was established between $\triangle p_{t}$ and $\triangle p_{c t}$. The capillary force caused a reorientation of the meniscus shape in the measurement tube. HFE-7500 has a contact angle of $0^{\circ}$ with the acrylic glass, and the radius of curvature of the liquid meniscus became equal to the tube radius. The reorientation time was calculated as $0.1 \mathrm{~s}$ Stange et al. (2003). The time $t=0 \mathrm{~s}$ corresponds to the first recorded image of the camera units. The first vertical line from the left represents the opening time of valve V5, and the tube was exposed to the ambient pressure. $\Delta p_{t}$ reduced to zero, and $\Delta p_{c t}$ approached its initial state slowly. With the initial state, we define the instant of time when we first applied the LPR suction pressure on the tube to extract the liquid from the channel. We assume the screen characteristics influence the slow change in $\Delta p_{c t}$. The liquid from the tube shall be transported back into the channel to reach the initial state. But the liquid flow rate through the screen is affected by the differential pressure across it. This behavior was observed in all the experiments;

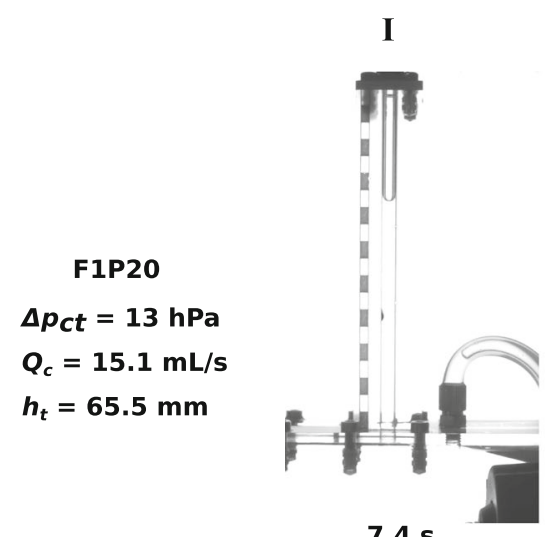

$7.4 \mathrm{~s}$

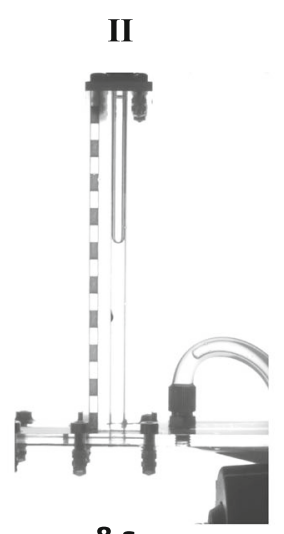

$8 \mathrm{~s}$

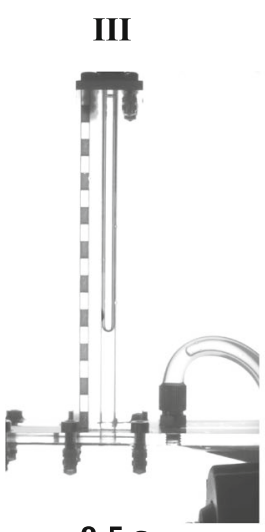

$9.5 \mathrm{~s}$

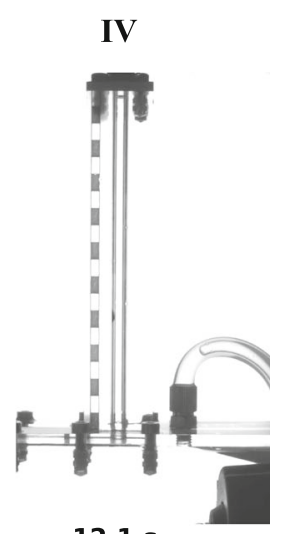

$12.1 \mathrm{~s}$
F2P13

$\Delta p_{c t}=17 \mathrm{hPa}$

$Q_{c}=15.9 \mathrm{~mL} / \mathrm{s}$

$h_{t}=72.1 \mathrm{~mm}$

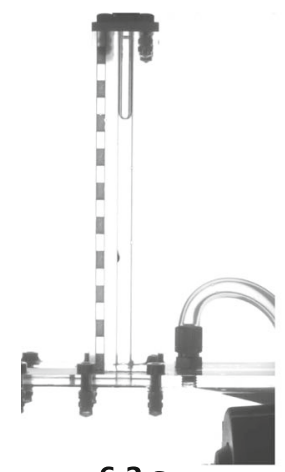

$6.2 \mathrm{~s}$

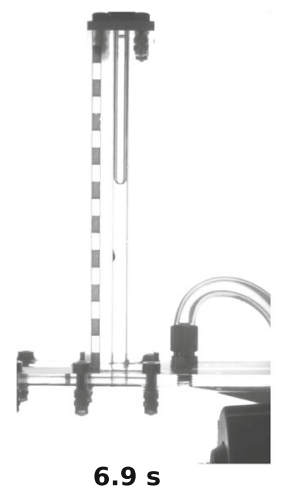

$6.9 \mathrm{~s}$

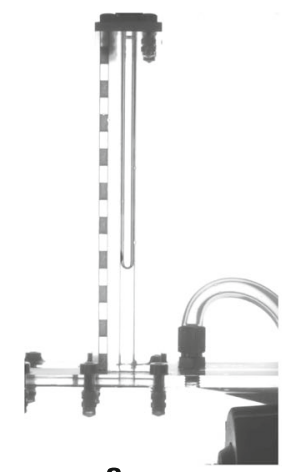

$8 \mathrm{~s}$

$7.2 \mathrm{~s}$

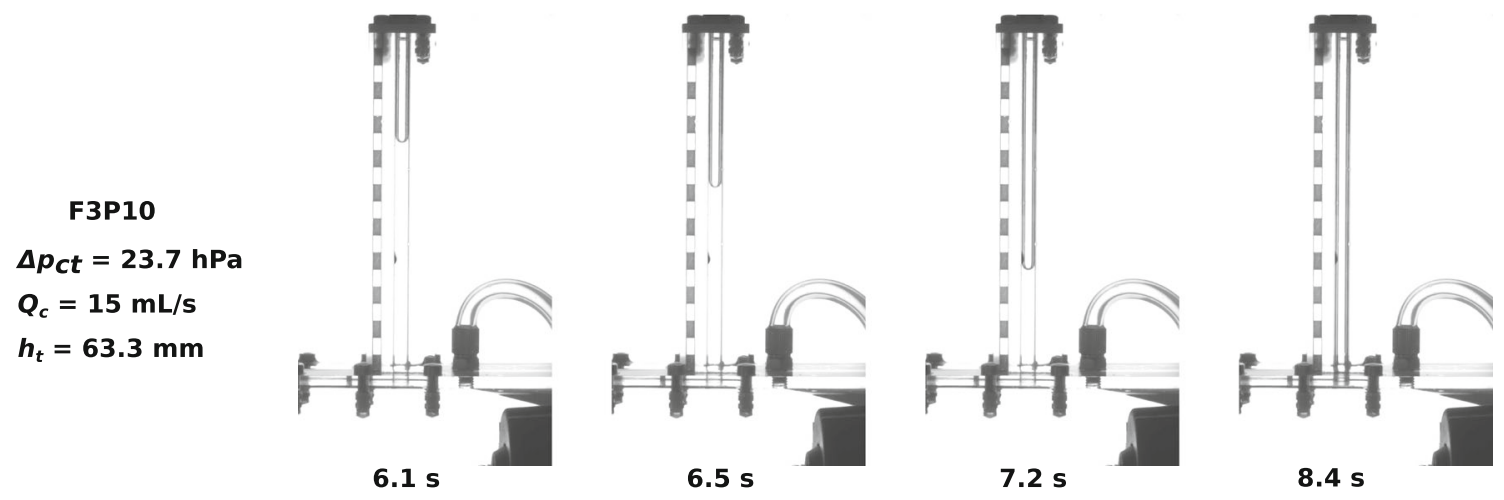

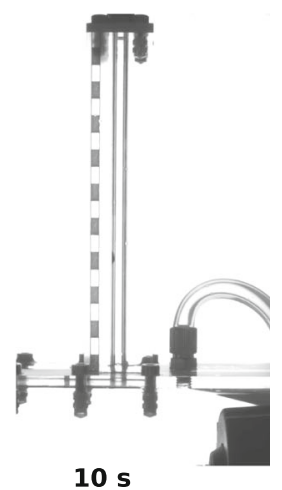

$10 \mathrm{~s}$

Fig. 6 The images show the liquid level in the measurement tube for experiments F1P20, F2P13, and F3P10 during the compensated gravity phase at different time intervals. The differential pressure across the porous screen drives the liquid through section $S_{2}$ into the channel 


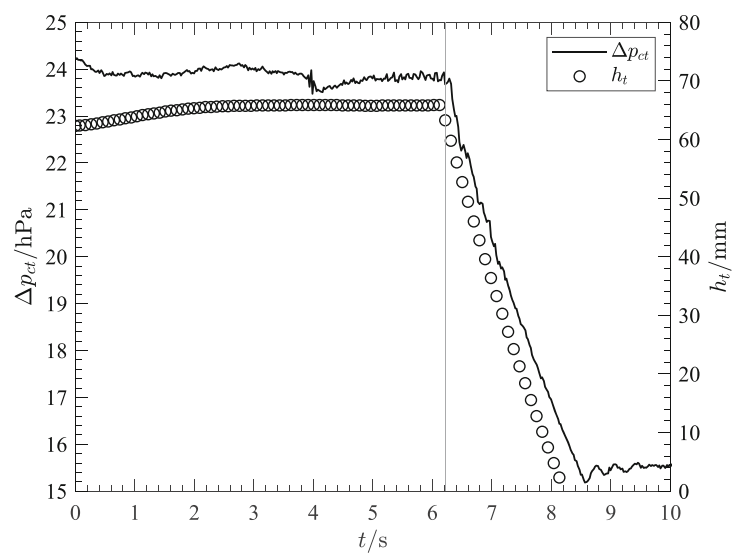

Fig. 7 Differential pressure $\Delta p_{c t}$ and liquid height $h_{t}$ in the measurement tube versus time for experiment F3P10. The rate of liquid withdrawal $Q_{t}$ was calculated from the change of the liquid height $h_{t}$ in the measurement tube. The horizontal error bar is $\pm 0.1 \mathrm{~s}$ for the

the system returned to its original state faster for higher values of $\Delta p_{c t}$. The circular mark represents the time when the liquid meniscus in the tube reaches the screen section $S_{2}$. The second vertical line from the left represents the closing of the valve V5. The second transition phase started at $t=19 \mathrm{~s}$ and was followed by a hypergravity phase.

\section{Phase Separation}

With $Q_{c}=0$, the system pressure remains in equilibrium, $p_{0}=p_{1}=p_{a}$ (Fig. 1). If a liquid flow rate is established in the channel, a pressure drop is induced along the length of the channel. The pressure at position 1 gets smaller

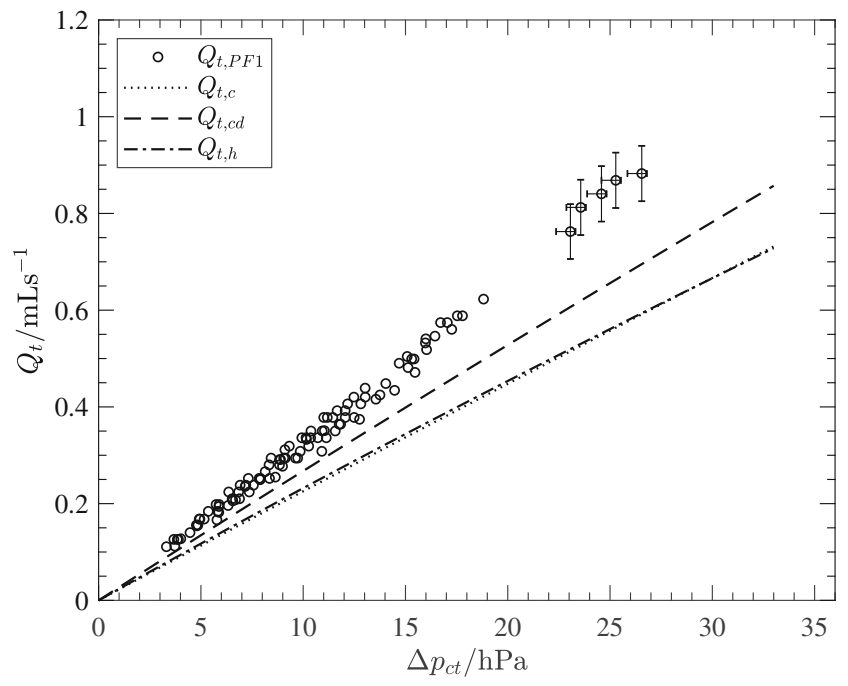

Fig. 8 Liquid flow rate $Q_{t}$ in the measurement tube with respect to the differential pressure for day 1 experiments. The vertical error bar for $Q_{t}$ is $\pm 0.06 \mathrm{~mL} \mathrm{~s}^{-1}$. The horizontal error bar is in the range of $-0.7 \mathrm{hPa}$ to $+0.25 \mathrm{hPa}$. The analytical flow rates following (Cady 1973) $Q_{t, c}$, Conrath and Dreyer (2012) $Q_{t, c d}$, and Hartwig (2016b) $Q_{t, h}$ were calculated with values from Table 1 . The liquid properties are taken at $20^{\circ} \mathrm{C}$

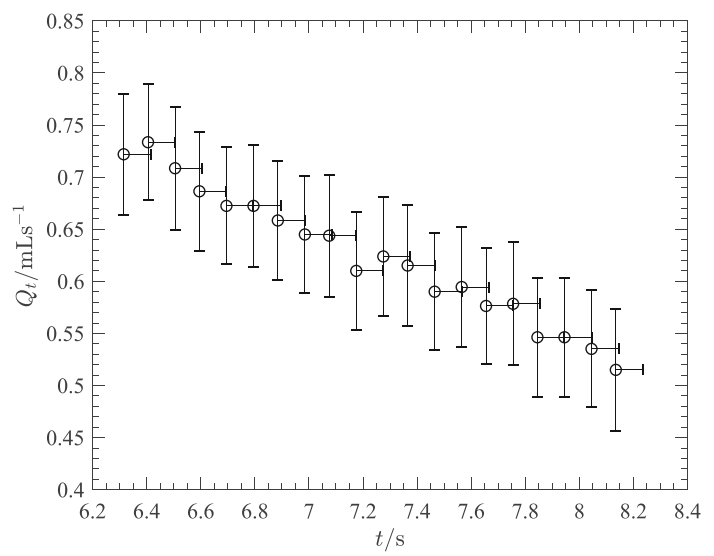

height $h_{t}$ and liquid flow rate $Q_{t}$. The vertical error bar for the height $h_{t}$ is $\pm 0.14 \mathrm{~mm}$. The vertical error bar for $Q_{t}$ is $\pm 0.06 \mathrm{~mL} \mathrm{~s}^{-1} . t=0$ $\mathrm{s}$ corresponds to the time of the first recorded image of the camera units

than the pressure at position $0, p_{1}<p_{0}$. The pressure difference across the screen section $S_{2}$ drives the liquid from the measurement tube into the channel. The rate of the liquid withdrawal is determined by the flow-throughscreen resistance of the porous medium and the differential pressure across screen section $S_{2}$. The total pressure loss in the channel can be determined from Rosendahl et al. (2004). The pressure drop from the entrance nozzle to the screen section $S_{2}$ (including the pressure drop of the converging nozzle) was calculated to be $25 \mathrm{~Pa}$ for a maximum liquid flow rate $Q_{c}=15 \mathrm{~mL} \mathrm{~s}^{-1}$. This pressure difference is very small compared to the differential pressure across the screen, hence it is neglected in the data evaluation. Three experiments (IDs F1P20, F2P13, and F3P10) were chosen to show the performance of the test setup for each flight

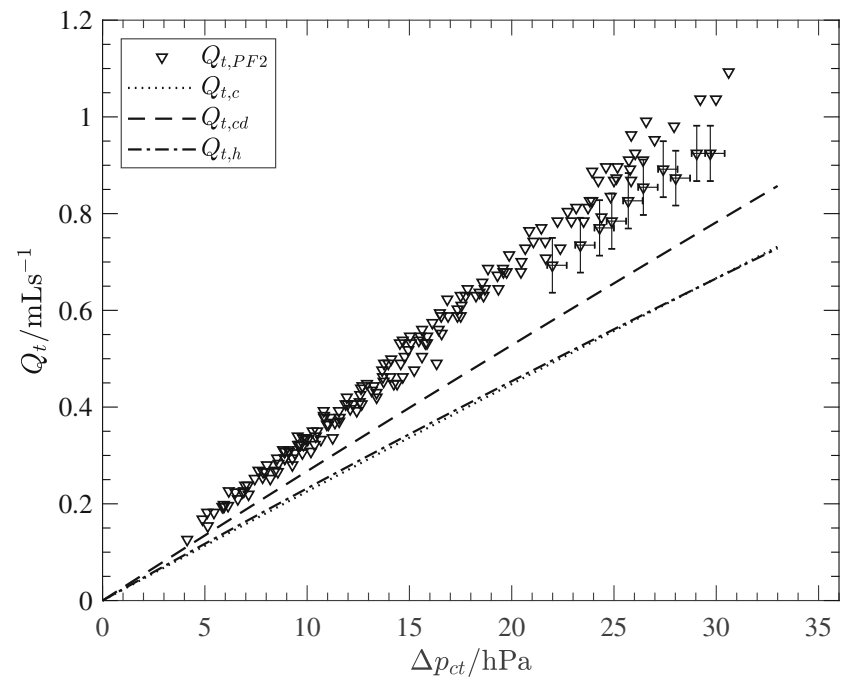

Fig. 9 Liquid flow rate $Q_{t}$ in the measurement tube with respect to the differential pressure for day 2 experiments. The vertical error bar for $Q_{t}$ is $\pm 0.06 \mathrm{~mL} \mathrm{~s}^{-1}$. The horizontal error bar is in the range of $-0.25 \mathrm{hPa}$ to $+0.7 \mathrm{hPa}$ 


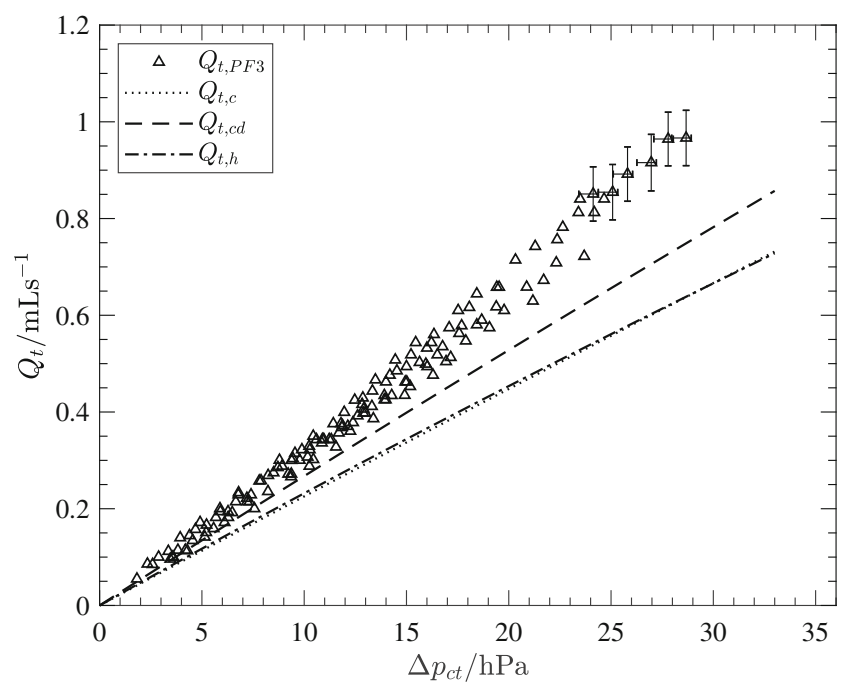

Fig. 10 Liquid flow rate $Q_{t}$ in the measurement tube with respect to the differential pressure for flight day 3 experiments. The vertical error bar for $Q_{t}$ is $\pm 0.06 \mathrm{~mL} \mathrm{~s}^{-1}$. The horizontal error bar is in the range of $-0.7 \mathrm{hPa}$ to $+0.25 \mathrm{hPa}$

day (see Fig. 6). Experiment F1P20 had the lowest $\Delta p_{c t}$, and experiment F3P10 had the highest $\Delta p_{c t}$, as shown in Tables 3, 4, and 5. The images represent the state of the liquid meniscus at different time instances. The first set of images (I) was taken at the time of valve V5 opening. In sets (II) and (III), the liquid meniscus in the measurement tube is moving downward. In set (IV), liquid meniscus in the tube reached to screen. The higher differential pressure across the screen resulted in a higher liquid withdrawal rate. The saturated screen section $S_{1}$ acts as a barrier to the ambient

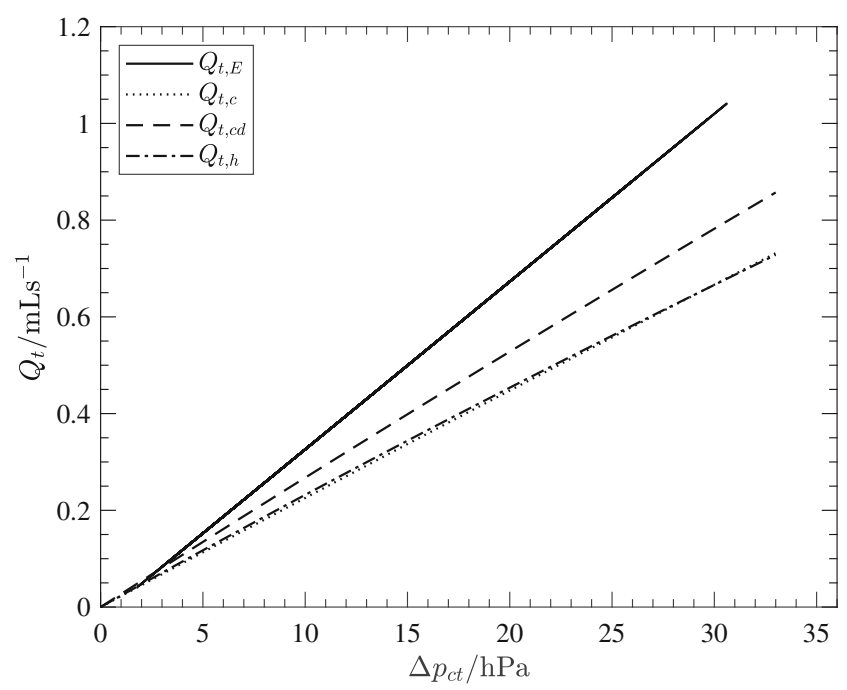

Fig. 11 Least-square fits of the liquid flow rate $Q_{t, E}$ for flight day 1,2 and 3 experiments with respect to the differential pressure. The vertical error bar for $Q_{t, E}$ is $\pm 0.06 \mathrm{~mL} \mathrm{~s}^{-1}$

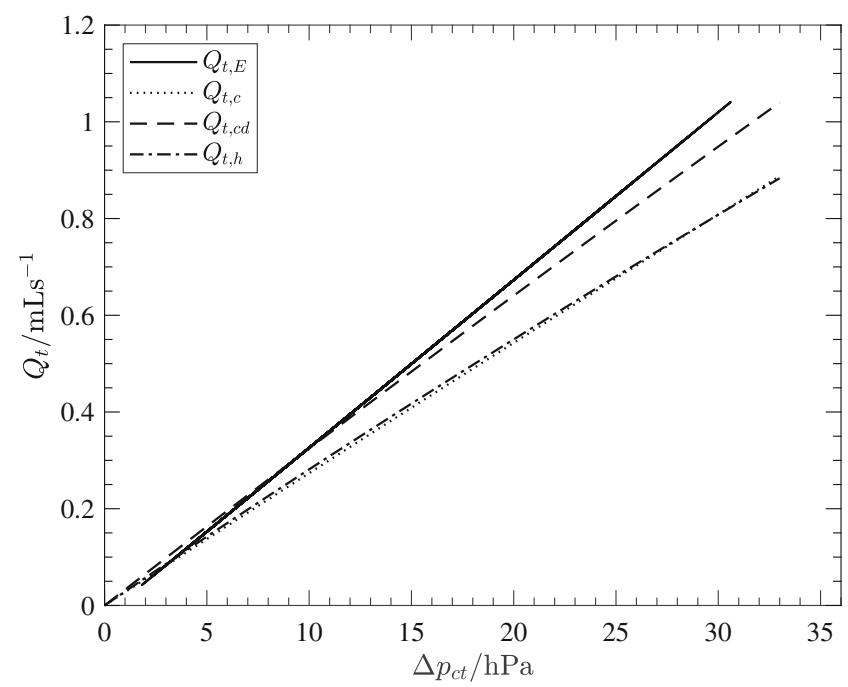

Fig. 12 Analytical solution based on the recomputed screen area $S_{2}$ and least-square fit for $Q_{t, E}$ experimental data. The vertical error bar for $Q_{t, E}$ is $\pm 0.06 \mathrm{~mL} \mathrm{~s}^{-1}$

gas, no gas breakthrough into the channel was observed during phase separation experiments.

The recorded images were processed to detect the position of the liquid meniscus in the measurement tube. Figure 7 shows the differential pressure $\triangle p_{c t}$, the liquid height $h_{t}$, and flow rate $Q_{t}$ in the measurement tube for experiment F3P10. The liquid height $h_{t}$ was determined in the center of the tube with an error of 2 to 3 pixels, which corresponds to $0.14 \mathrm{~mm}$. The left picture depicts $h_{t}$ and the corresponding $\triangle p_{c t}$ with respect to the experiment time. At $t=0 \mathrm{~s}$, all camera units were started to record the images. The vertical line indicates the opening of the valve V5. The

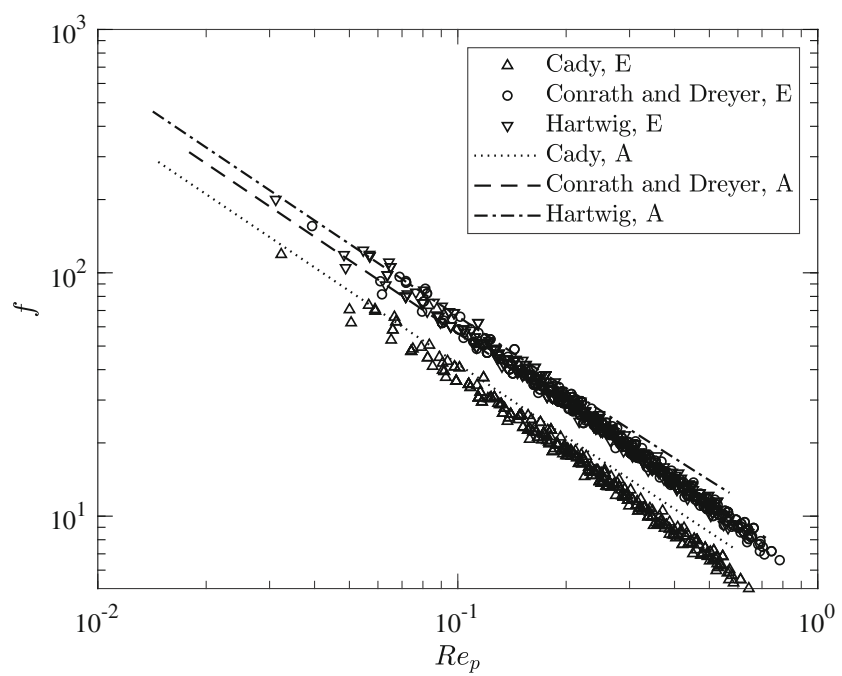

Fig. 13 Friction factor $f$ as a function of the pore Reynolds number $\operatorname{Re}_{p}$. The recomputed data from the experiments are denoted with the letter E. The analytical solutions are denoted with the letter A 
right picture in Fig. 7 shows $Q_{t}$ in the tube after opening the valve V5. $Q_{t}$ was calculated by subtracting the height $h_{t}$ at a time interval $t_{1}$ from the previously recorded height at $t_{0}$. The difference in height over the time interval $\Delta t=0.1 \mathrm{~s}$ is used to compute the liquid flow rate $Q_{t}$ in the tube.

Figures 8,9 and 10 show $Q_{t}$ relative to $\Delta p_{c t}$ for flight day 1,2 , and 3 experiments, respectively. The analytical solution is obtained using (3) and the screen properties from Table 1. We performed least-square fits for all collected data points and compared it with the analytical solutions in Fig. 11. The liquid flow rate $Q_{t, E}$ from the experiments is closest to the Conrath and Dreyer (2012) data. However, all analytical calculations under-predict the flow rate. We assumed that this deviation is due to an error in the calculation of the effective screen section $S_{2}$. We observed that some part of $S_{2}$ outside the $5 \mathrm{~mm}$ diameter region was not covered with sealant (Fig. 3). The screen in the defined area was also not attached to the channel surface
Fig. 14 Video images from experiments F3P15, F3P20, and F3P25 during the compensated gravity phase at different time intervals. In the first two columns (set I and II), the differential pressure across the screen remains lower than the bubble point pressure, and the saturated screen section $S_{1}$ blocks gas ingestion. The gas breakthrough occurs when the differential pressure exceeds the bubble point pressure, as shown in the third column (set III)
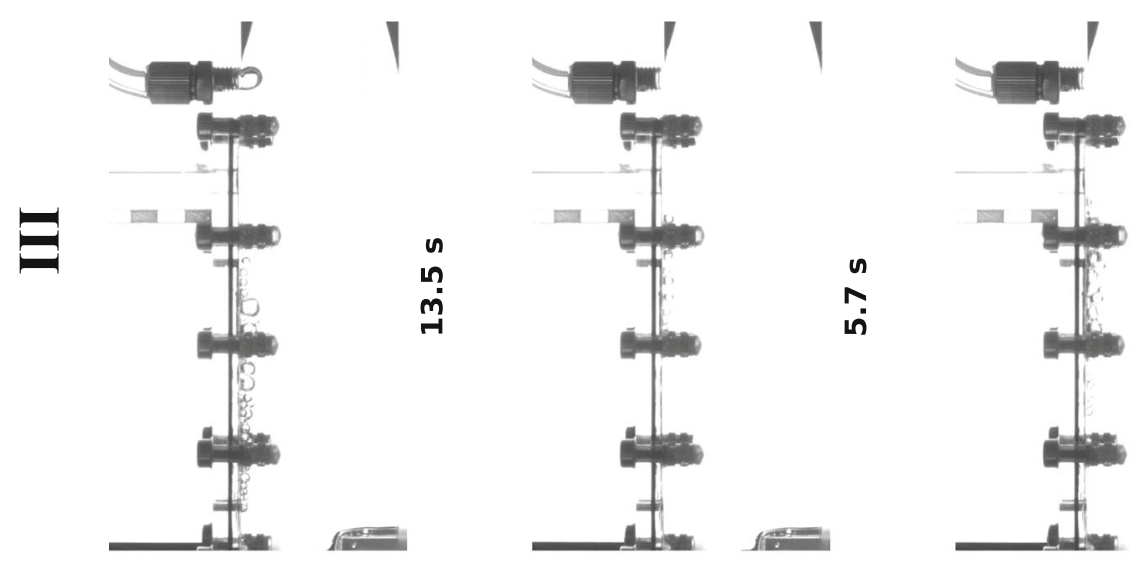

$1=$
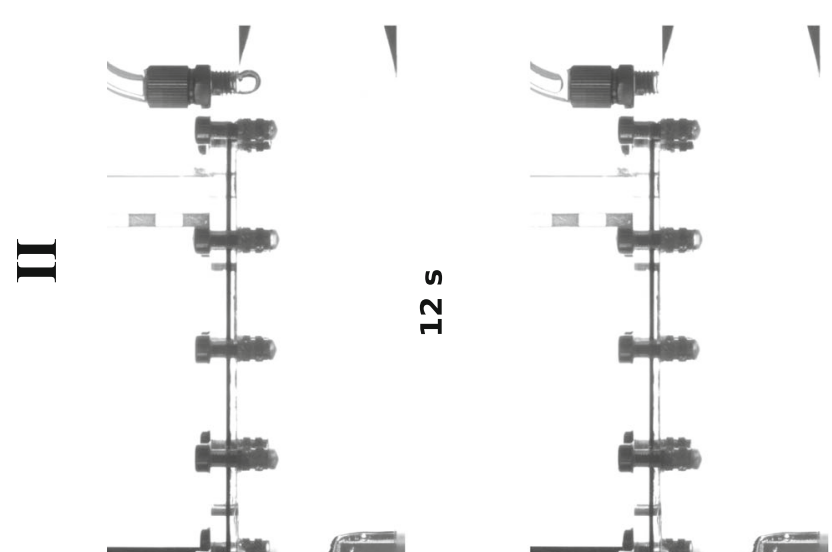

v
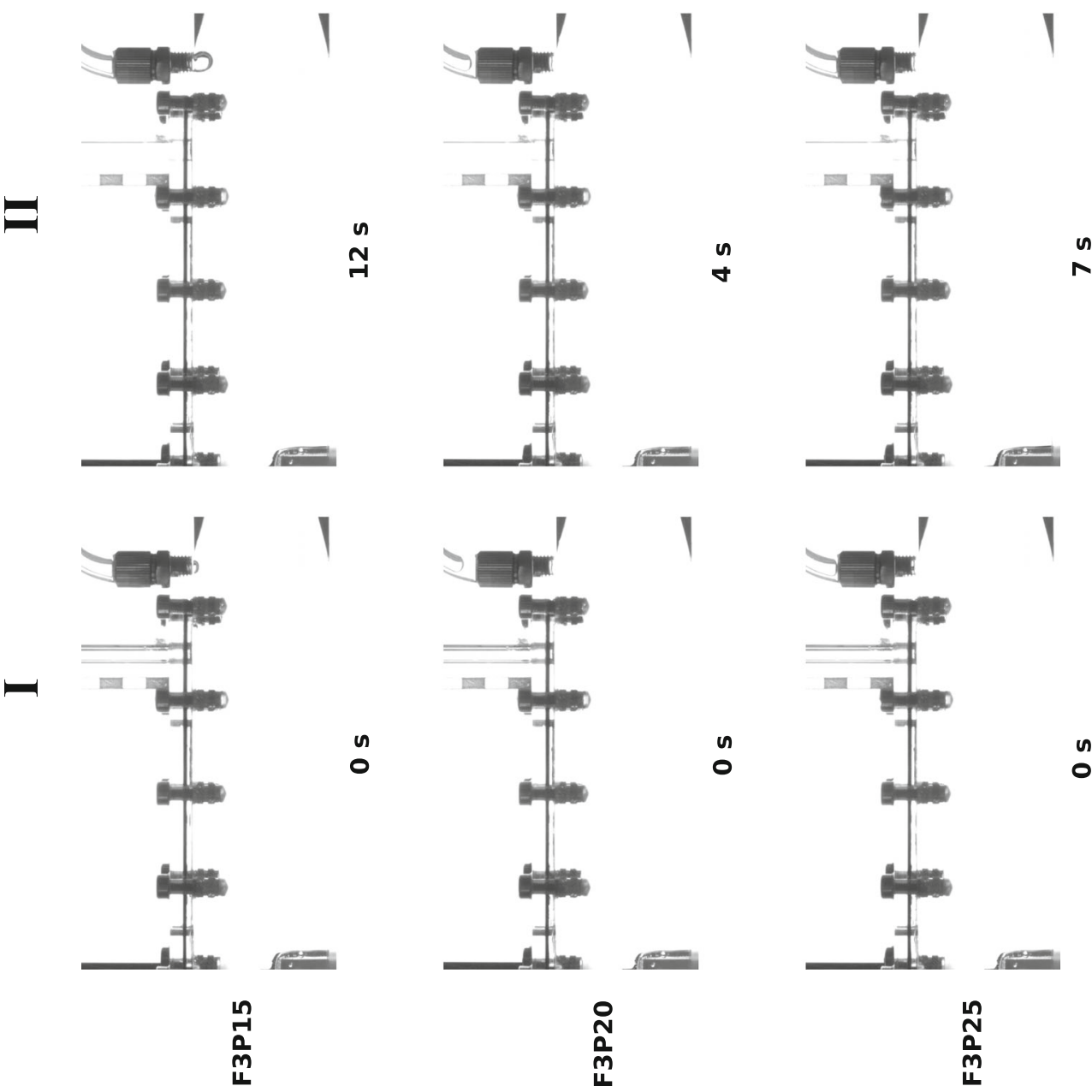

n

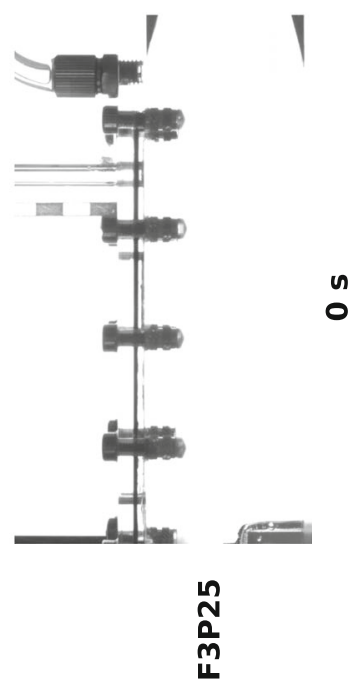




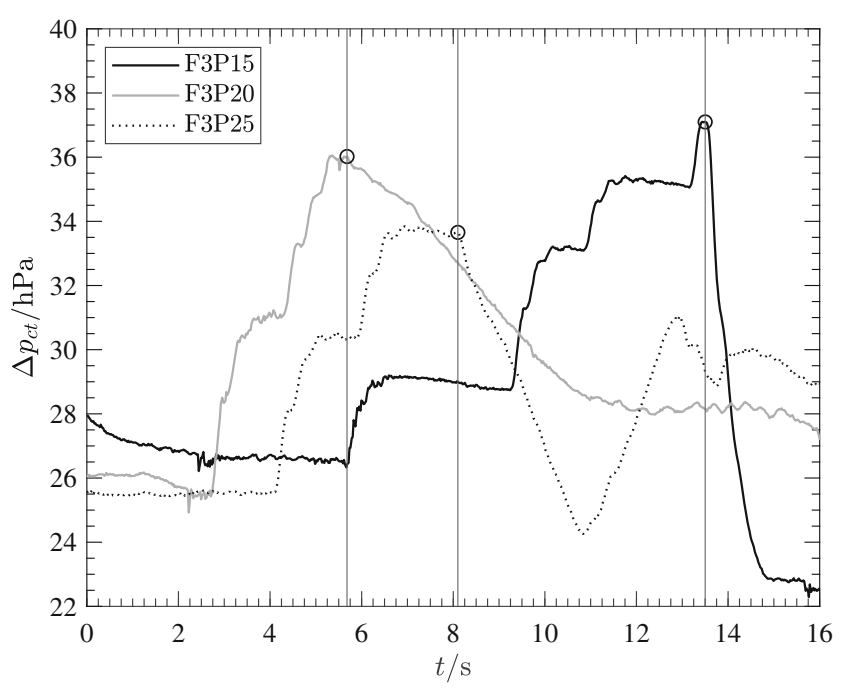

Fig. 15 Experimentally measured bubble point pressure for compensated gravity experiments. We increased the differential pressure across the screen in a stepwise manner. When the differential pressure exceeded the bubble point limit, the gas breakthrough occurred, and the differential pressure dropped. The circular marks and vertical lines represent the occurrence of gas breakthrough

and acted as an open space for the liquid flow. The open area $A_{S_{2}}$ of the screen section $S_{2}$ may be as large as $21.6 \mathrm{~mm}^{2}$. The analytical solution based on this new area $A_{S_{2}}=21.6 \mathrm{~mm}^{2}$ shows better agreement with the experiment data (see Fig. 12).

We analyze our data with regard to the correlations for the flow-through-screen pressure drop from "State of the Art". We take the pressure drop $\triangle p_{c t}$ as the dependent variable (in the form of a friction factor $f$ ) and plot it against the superficial velocity $u_{s}$ as the independent variable (in

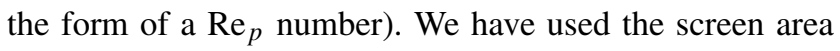

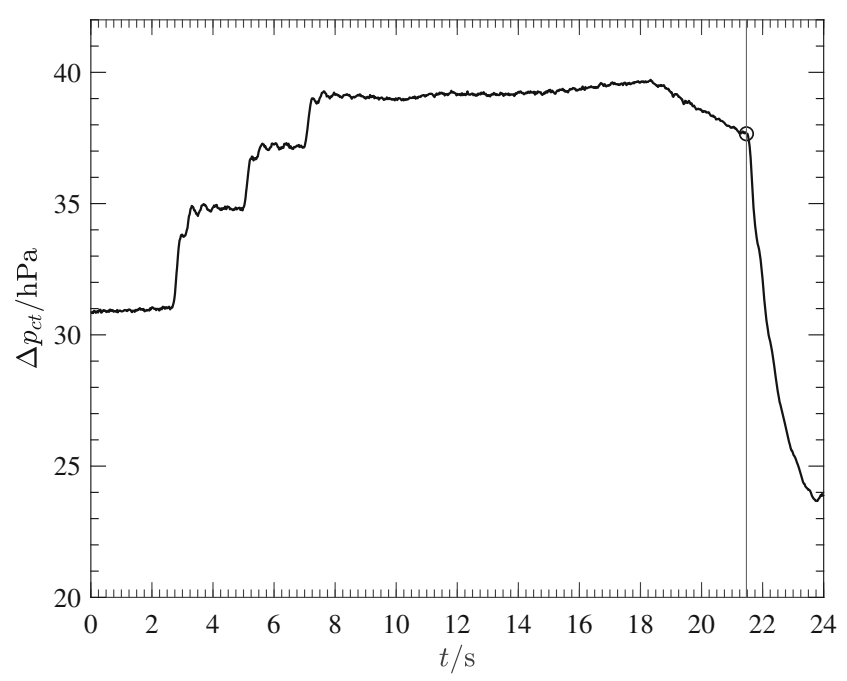

Fig. 16 Experimentally measured bubble point pressure for hypergravity experiment F3P30
$A_{S_{2}}=21.6 \mathrm{~mm}^{2}$. Each data point from Figs. 8, 9 and 10 is converted using the screen properties from Table 1. The screen parameters differ between different authors. The porosity reported by Cady (1973) has the highest difference. This has, together with a smaller $C_{1}$, a remarkable effect on the friction factor. All other screen parameters except $C_{1}$, $C_{2}$, and $\phi$ are within a $\pm 10 \%$ variation.

We have marked the different results with different symbols in Fig. 13: $\triangle$ for Cady (1973), $\bigcirc$ for Conrath and Dreyer (2012), and $\nabla$ for Hartwig (Hartwig 2016b). Our experimental results, reorganized in the from $f=f\left(\operatorname{Re}_{p}\right)$, are then compared with the correlations themselves.

Figure 13 reveals that our data recomputed with the data from Cady (1973) lead to a smaller friction factor than the data from Conrath and Dreyer (2012) and Hartwig (2016b). This was not visible in Fig. 11. All data points are in the range $0.01 \leq \operatorname{Re}_{p} \leq 1$. Therefor, the second term in Eq. 7 is negligible. We conclude that the differences in Figs. 8, 9 and 10 cannot be explained by the differences in the correlations. The largest source of error is the estimation of the effective screen area.

\section{Bubble Point Pressure Test}

We investigated the static bubble point of the porous screen in compensated gravity with experiments F2P30, F3P15, F3P20, F3P25, and in hypergravity with experiments F3P29, and F3P30. During the parabolic trajectory of the airplane (and the residual accelerations of $10^{-3} g_{e}$ associated with it), the liquid in the compensation tube moved and covered lines to the valves V1 and V3. To prevent flooding of the gas lines, the valves connected to the CT remained closed for bubble point experiments. The pressure in the channel was reduced in a stepwise manner by opening valve V6, which connects the measurement tube to the LPR. The images in $x z$-plane for experiments F3P15, F3P20, and F3P25 are shown in Fig. 14 at different time intervals. At $t=0 \mathrm{~s}$ (set I), both screen sections $S_{1}$ and $S_{2}$ were exposed to ambient pressure.

To established a differential pressure across the screen, valve V6 was opened for a short time interval and then closed. The sequential opening and closing of valve V6 allowed to control the LPR suction pressure on the screen section $S_{2}$. The suction pressure is recorded as $\Delta p_{t}$ by a differential pressure sensor located at the top end of the measurement tube. Due to the applied suction pressure, the pressure in the channel is reduced, and liquid moved into the tube from the channel. The screen section $S_{2}$ was submerged in liquid, and only $S_{1}$ was open to the ambient gas. This can be seen in set II of Fig. 14. Depending on the applied pressure, the channel pressure reduced further, and liquid continued to rise in the tube until the differential pressure 
Table 6 Analytically $\triangle p_{b p_{A}}$ and experimentally $\triangle p_{b p_{E}}$ determined bubble point pressures for compensated gravity and hypergravity experiments. The value for $C_{0}$ are varied as $0.648 \leq C_{0} \leq 0.705$. The absolute pore diameter $D_{p}=(13 \pm 1) \mu \mathrm{m}$ was taken from the screen manufacturer (Spoerl 2019). The bubble point diameter $D_{b p}$ is calculated from Eq. 1

\begin{tabular}{lllllll}
\hline Exp.ID & $T /{ }^{\circ} \mathrm{C}$ & $\sigma / \mathrm{mN} \mathrm{m}^{-1}$ & $\Delta p_{b p_{A}} / \mathrm{hPa}$ & $\Delta p_{b p_{E}} / \mathrm{hPa}$ & $D_{b p} / \mu \mathrm{m}$ & $D_{b p(\text { average })} / \mu \mathrm{m}$ \\
\hline F3P15 & 19.2 & 17.23 & $36.0 \pm 4.2$ & $37.0 \pm 0.25$ & $18.63 \pm 0.12$ \\
F3P20 & 21.4 & 17.02 & $35.6 \pm 4.2$ & $36.0 \pm 0.25$ & $18.91 \pm 0.12$ & $18.83 \pm 0.12$ \\
F3P25 & 23.2 & 16.84 & $35.2 \pm 4.2$ & $33.6 \pm 0.25$ & $20.05 \pm 0.15$ \\
F3P30 & 24.6 & 16.70 & $34.9 \pm 4.2$ & $37.7 \pm 0.25$ & $17.72 \pm 0.12$ \\
\hline
\end{tabular}

$\triangle p_{c t}$ remained below the bubble point pressure $\triangle p_{b p}$ of the screen. The gas breakthrough occurred through screen section $S_{1}$ when $\triangle p_{c t}$ exceeded $\triangle p_{b p}$, as shown in set III of Fig. 14. The ingested gas formed bubbles, which detached due to the shear force of the liquid flow in the channel. The bubbles moved with the liquid and coalesced to larger non-circular bubbles.

The change in differential pressure versus time is shown in Figs. 15 and 16 for experiments F3P15, F3P20, F3P25, and F3P30. The vertical lines and circular marks represent the event of the bubble breakthrough. The applied differential pressure was reduced at the bubble point and then continues to recede until the pores become saturated again and block further gas ingestion. The ingested gas moves with the liquid flow. It is stored in the phase separator and does not enter the channel again. We compare experimental values with the theoretical results in Table 6 . The data shows good agreement for all experiments. The analytical solution is based on Eqs. 1 and 2. The average of the experimentally obtained bubble point diameter is calculated to be $(18.83 \pm 0.12) \mu \mathrm{m}$. For experiments F2P30 and $\mathrm{F} 3 \mathrm{P} 29$, the liquid in the measurement tube reached the top end while increasing the differential pressure in the channel. We stopped the experiments before the bubble point limit of the screen could be reached to prevent the flooding of the gas lines. In Table 7, DTW $200 \times 1400$ $\triangle p_{b p}$ values are listed for storable and cryogenic liquid experiments and the measured $D_{b p}$ is compared. The 4 data points of the current study are plotted with historical bubble point pressure against the surface tension in Fig. 17. A data fit is provided for the comparison with other studies.

\section{Conclusion}

We developed a test facility to investigate phase separation and the occurrence of bubble ingestion in a porous screen integrated rectangular capillary channel. The liquid withdrawal into the channel from its surroundings was evaluated in a compensated gravity environment and compared with the analytical values. The analytical solution is based on the screen properties, as reported by different authors. The comparison shows that the analytical result under-predicts the liquid flow rate $Q_{t}$ across the screen. The theoretical results were corrected by recomputing the open area of the screen, which shows better agreement with the experimental data. We did not observe a gas breakthrough during the phase separation experiments.

We performed bubble point experiments in a compensated gravity as well as in a hypergravity environment. We observed the occurrence of a gas breakthrough when the differential pressure across the screen exceeded the bubble point pressure limit. The measured bubble points are within the predicted range for all experiments.

We performed our parametric study by varying the compensation tube differential pressure $\Delta p_{c t}$, the liquid flow rate in the channel $Q_{c}$, and liquid column height $h_{t}$ in the measurement tube. The results show that a porous

Table 7 Historical bubble point pressure $\triangle p_{b p}$ and diameter $D_{b p}$ for DTW $200 \times 1400$ in literature

\begin{tabular}{llll}
\hline Reference & Liquid and conditions & $\sigma / \mathrm{mN} \mathrm{m}^{-1}$ & $\Delta p_{b p} / \mathrm{hPa}$ \\
\hline Cady (1973) & LH2 $(25.2 \mathrm{~K}, 3.45 \mathrm{bar})$ & 1.178 & 2.1 \\
Pingel and Dreyer (2019) & LH2 (20.4 K) & 1.9 & $4.26 \pm 0.26$ \\
Conrath and Dreyer (2012) & SF0.65 (295 K) & 15.9 & 31.8 \\
Kudlac and Jurns (2006) & LN2 & 8.75 & 16.5 \\
Kudlac and Jurns (2006) & LOX & 13.2 & 23.75 \\
Kudlac and Jurns (2006) & IPA & 22 & 38.75 \\
\hline
\end{tabular}




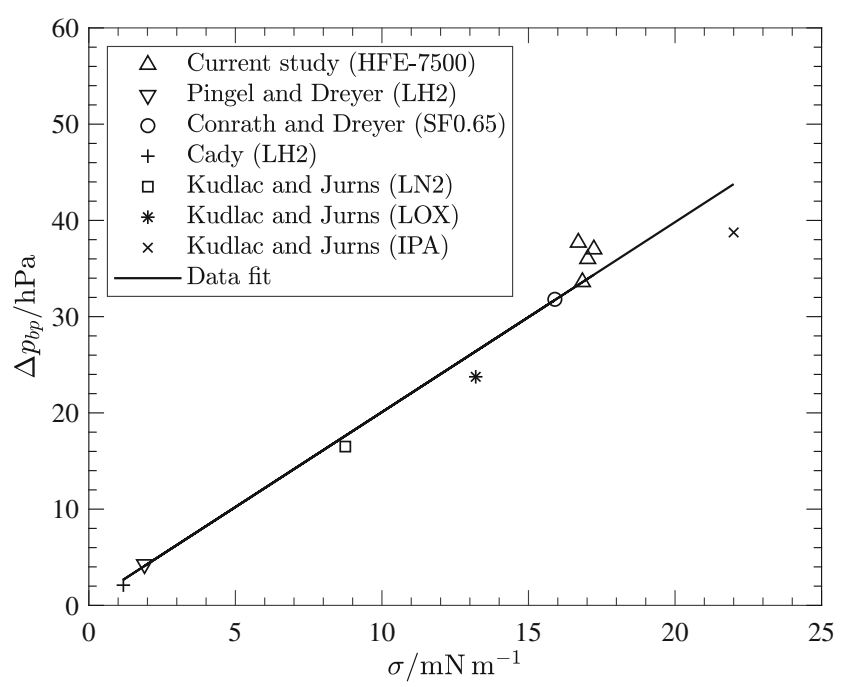

Fig. 17 Historical and current study bubble point pressure related to the surface tension $\sigma$ of the test liquid

medium can be used as a passive phase separator. The combination of the bubble point pressure and the flowthrough-screen pressure (correlations available in literature) can be used to design screen channel liquid acquisition devices. SCLAD can be used in different application, where gas-free liquid removal without the help of the hydrostatic pressure is required.

Acknowledgements The project under grant number 50WM1745 is funded by the means of the German Federal Ministry of Economics and Technology (BMWi) through the German Aerospace Center (DLR e.V.). The authors acknowledge the support provided by Holger Faust, Ronald Mairose, and Marcel Bernauer. We also acknowledge the support of Vishwas Kulkarni for helping with the data evaluation. We are grateful for the reviews comments. In particular the display of the flow-through-screen pressure helps to understand the differences in the results.

Funding Open Access funding provided by Projekt DEAL.

\section{Compliance with Ethical Standards}

Conflict of interests The authors declare no conflict of interest.

Open Access This article is licensed under a Creative Commons Attribution 4.0 International License, which permits use, sharing, adaptation, distribution and reproduction in any medium or format, as long as you give appropriate credit to the original author(s) and the source, provide a link to the Creative Commons licence, and indicate if changes were made. The images or other third party material in this article are included in the article's Creative Commons licence, unless indicated otherwise in a credit line to the material. If material is not included in the article's Creative Commons licence and your intended use is not permitted by statutory regulation or exceeds the permitted use, you will need to obtain permission directly from the copyright holder. To view a copy of this licence, visit http:// creativecommonshorg/licenses/by/4.0/.

\section{References}

Armour, J.C., Cannon, J.N.: Fluid flow through woven screens. AIChE J. 14, 415-420 (1968)

Bronowicki, P., Canfield, P., Grah, A., Dreyer, M.E.: Free surfaces in open capillary channels - parallel plates, Phys. Fluids 27.012106, pp. 1-21 (2015)

Cady, E.C.: Study of thermodynamic vent and screen baffle integration for orbital storage and transfer of liquid hydrogen, NASA Report No CR-134482 (1973)

Camarotti, C., Deng, O., Darr, S., Hartwig, J., Chung, J.N.: Room temperature bubble point, flow-through screen and wicking experiments for screen channel liquid acquisition devices. Appl. Therm. Eng. 149, 1170-1185 (2019a)

Camarotti, C., Deng, O., Darr, S., Hartwig, J., Chung, J.N.: Screen compliance experiments for application of liquid acquisition device in space, microgravity Sci. Technol. 31.1, pp. 109-122 (2019b)

Canfield, P.J., Bronowicki, P.M., Chen, Y., Kiewidt, L., Grah, A., Klatte, J., Jenson, R., Blackmore, W., Weislogel, M.M., Dreyer, M.E.: The capillary channel flow experiments on the international space station: experiment set-up and first results, Exp. Fluids 54.1519, pp. 1-14 (2013)

Conrath, M., Dreyer, M.E.: Gas breakthrough at a porous screen. Int. J. Multiphase Flow 42, 29-41 (2012)

Conrath, M., Smiyukha, Y., Fuhrmann, E., Dreyer, M.E.: Double porous screen element for gas-liquid phase separation. Int. J. Multiphas. Flow 50, 1-15 (2013)

Darr, S., Hartwig, J.W.: Optimal liquid acquisition device screen weave for a liquid hydrogen fuel depot. Int. J. Hydrogen Energ. 39.9, pp. 4356-4366 (2014)

Dushin, V.R., Nikitin, V.F., Smirnov, N.N., Skryleva, E.I., Tyurenkova, V.V.: Microgravity investigation of capillary driven imbibition, microgravity Sci. Technol. 30, pp. 393-398 (2018)

Fries, N., Odic, K., Conrath, M., Dreyer, M.E.: The effect of evaporation on the wicking of liquids into a metallic weave. J. Colloid Interf. Sci. 321.1, pp. 118-129 (2008)

Grah, A., Canfield, P.J., Bronowicki, P.M., Dreyer, M.E., Chen, Y., Weislogel, M.M.: Transient capillary channel flow stability. Microgravity Sci. Technol. 26.6, pp. 385-396 (2014)

Hartwig, J.: Screen channel liquid acquisition device bubble point tests in liquid nitrogen. Cryogenics 74, 95-105 (2016a)

Hartwig, J.W.: Liquid acquisition devices for advanced in-space cryogenic propulsion systems. Elsevier, New York (2016b)

Hartwig, J., Chato, D., Mcquillen, J., Screen channel, L.AD.: Bubble point tests in liquid hydrogen. Int. J. Hydrogen Energ. 39.2, pp. 853-861 (2014)

Hartwig, J., Darr, S.: Influential factors for liquid acquisition device screen selection for cryogenic propulsion systems. Appl. Therm. Eng. 66.1-2, pp. 548-562 (2014)

Hartwig, J., Mcquillen, J.: Screen channel liquid-acquisition-device bubble point tests in liquid oxygen. J. Thermophys. Heat Tr. 29.2, pp. 353-363 (2015)

Jaekle, D.E. Jr.: Propellant management device conceptual design and analysis: Vanes. In: AIAA/SAE/ASME/ASEE 27th joint propulsion conference, June, pp. 24-26 (1991)

Jaekle, D.E. Jr.: Propellant management device conceptual design and analysis: Galleries. In: AIAA/SAE/ASME/ASEE 33rd joint propulsion conference and exhibit, July, pp. 6-9 (1997)

Kudlac, M.T., Jurns, J.M.: Screen channel liquid acquisition devices for liquid oxygen, 42nd AIAA/ASME/SAE/ASEE joint propulsion conference and exhibit., Sacramento, CA, AIAA (2006)

Pingel, A., Dreyer, M.E.: Phase separation of liquid from gaseous hydrogen in microgravity experimental results, microgravity Sci. Technol. 31.5, pp. 649-671 (2019) 
Rollins, J.R., Grove, R.K., Jaekle, D.E. Jr.: Twenty-three years of surface tension propellant management system design, development, manufacture, test, and operation, 21st Joint Propulsion Conference AIAA-85-1199 (1985)

Rosendahl, U., Dreyer, M.: Design and performance of an experiment for the investigation of open capillary channel flows, Exp. Fluids 42.5, pp. 683-696 (2007)

Rosendahl, U., Ohlhoff, A., Dreyer, M.E.: Choked flows in open capillary channels: theory, experiment and computations. J. Fluid Mech. 518, 187-214 (2004)

Smirnov, N.N., Legros, J.C., Nikitin, V.K., Istasse, E., Schramm, L., Wassmuth, F., Hart, D.: Filtration in artificial porous media and natural sands under microgravity conditions, Microgravity Sci. Technol. 14.2, pp. 3-28 (2003)
Smirnov, N.N., Nikitin, V.F., Norkin, A.V., Kudryavtseva, O.V., Legros, J.C., Istasse, E., Shevtsova, V.M.: Capillary driven filtration in porous media, microgravity Sci. Technol. 12.1, pp. 23-35 (1999)

Spoerl: Spoerl KG high precision wire weaving. Screen material supplier, technical data sheet of dutch twilled weaves. http://www.spoerl.de/wp-content/uploads/2014/08/ Tabelle-K\%c3\%b6pertressen1.pdf (2019)

Stange, M., Dreyer, M.E., Rath, H.J.: Capillary driven flow in circular cylindrical tubes, Phys. Fluids 15.9, pp. 2587-2601 (2003)

Publisher's Note Springer Nature remains neutral with regard to jurisdictional claims in published maps and institutional affiliations. 